Check for updates

Cite this: RSC Adv., 2018, 8, 17656

Received 20th March 2018

Accepted 7th May 2018

DOI: $10.1039 / \mathrm{c} 8 \mathrm{ra02424c}$

rsc.li/rsc-advances

\section{Recent review of the effect of nanomaterials on stem cells}

\author{
Xu Zhou, $\dagger^{\mathrm{a}}$ Long Yuan, $\mathbb{D} \dagger^{\mathrm{b}}$ Chengzhou Wu, ${ }^{* c}$ Cheng chen, ${ }^{\mathrm{d}}$ Gaoxing Luo, ${ }^{\text {*e }}$ \\ Jun Deng (D) *e and Zhengwei Mao (iD ${ }^{f}$
}

The field of stem-cell-therapy offers considerable promise as a means of delivering new treatments for a wide range of diseases. Recent progress in nanotechnology has stimulated the development of multifunctional nanomaterials (NMs) for stem-cell-therapy. Several clinical trials based on the use of NMs are currently underway for stem-cell-therapy purposes, such as drug/gene delivery and imaging. However, the interactions between NMs and stem cells are far from being completed, and the effects of the NMs on cellular behavior need critical evaluation. In this review, the interactions between several types of mostly used NMs and stem cells, and their associated possible mechanisms are systematically discussed, with specific emphasis on the possible differentiation effects induced by NMs. It is expected that the enhanced understanding of NM-stem cell interactions will facilitate biomaterial design for stemcell-therapy and regenerative medicine applications.

\section{Introduction}

${ }^{a}$ Department of Ophthalmology, Southwest Hospital, Third Military Medical University (Army Medical University), Chongqing 400038, China

${ }^{b}$ Department of Breast Surgery, Southwest Hospital, Third Military Medical University (Army Medical University), Chongqing 400038, China

'Department of Respiratory, Wuxi Country People's Hospital, Chongqing 405800, China.E-mail: 164916377@qq.com

${ }^{d}$ Center for Joint Surgery, Southwest Hospital, Third Military Medical University (Army Medical University), Chongqing 400038, China

${ }^{e}$ Institute of Burn Research, Southwest Hospital, State Key Lab of Trauma, Burn and Combined Injury, Third Military Medical University (Army Medical University), Chongqing 400038, China.E-mail: logxw@yahoo.com; djun.123@163.com

${ }^{f} M O E$ Key Laboratory of Macromolecular Synthesis and Functionalization, Department of Polymer Science and Engineering, Zhejiang University, Hangzhou 310027, China $\dagger$ Co-first authors.

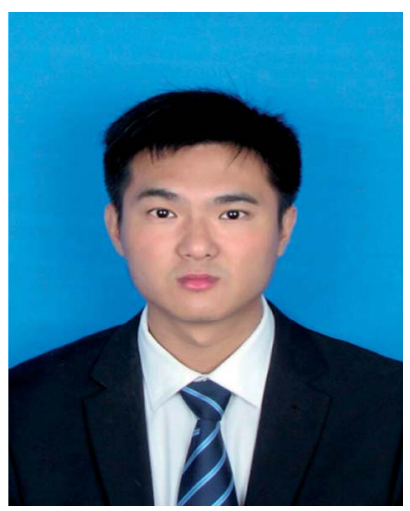

Jun Deng is associate Professor in Institute of Burn Research, Southwest Hospital, State Key Lab of Trauma, Burn and Combined Injury, Third Military Medical University (Army Medical University), China. He received his $P h D$ in Department of Polymer Science and Engineering, Zhejiang University, China. His research interest includes nanomaterials, cellnanomaterials interactions, hydrogels, wound healing, and tissue engineering.
Stem cells are a class of pluripotent cells with a strong selfrenewal capacity, and own the potential to differentiate into different lineages (e.g., osteoblasts, chondrocytes, adipocytes and etc.) given a certain stimulus. ${ }^{1}$ Generally, stem cells can be divided into three categories: embryonic stem cells (ESCs) are derived from the inner cell mass of a blastocyst, and are an ideal cell source for regenerative medicine due to their limitless selfrenewal and pluripotency. ${ }^{2}$ Nonetheless, some ethical problems were produced by using of the embryos to acquire ESCs; adult stem cells (ASCs) are found throughout the body after development. Despite with fewer ethical questions, ASCs have limited differentiation potential and self-renewal ability.,4 Therefore, induced pluripotent stem cells (iPSCs), as another type of commonly used stem cells, were generated by reprogramming somatic cells into pluripotent stem cells. Until today, the reprogramming efficiency is debatable. ${ }^{5}$ Even so, stem cells still have attracted particular interests in the field of generative medicine due to their ability of being cultured for successive passages and multi-lineage differentiation. ${ }^{6,7}$ However, some challenges include controlled self-renewal process, rapid proliferation, and well defined differentiation of stem cells must be addressed before they can be completely used in medical treatments.

Since the "nanotechnology" was firstly introduced by the Richard Feynman in 1959, it became more and more clear that miniaturization macroscopic counterparts can obtain novel or distinctive physical, optical, chemical and mechanical properties by nanotechnology. ${ }^{\mathbf{4}, \mathbf{8}}$ With the consideration that they could be rationally used to create novel and practical 
therapeutic and diagnostic tools, these unique properties have acquired the increasing interests of the medical and biological researches. Earlier examples of nanomaterials applied in stem cell therapy involved lipid- and polymer-based nanocarriers with encapsulated genes/drugs for targeted and controlled gene/drug release to modulate stem cell behaviors. ${ }^{9-12}$ Alongside, the novel medical applications of smaller, inorganicbased NPs with unique properties have deserved compelling sights in the development of "nanoprobes" for diagnostic medicine and agents for novel, externally activated therapies. Thus, many inorganic NPs including nanodiamonds (NDs) ${ }^{13}$ iron oxide NPs (IONPs) ${ }^{14}$ quantum dots (QDs) ${ }^{15}$ and upconversion NPs (UCNPs) ${ }^{16,17}$ have been applied for the labeling and tracking of stem cells. Moreover, materials, especially the synthetic materials due to the ease of synthesis and functionalization, have been constructed into structures with nanoscale features to provide an inductive microenvironment in which stem cells could be adapted to proliferate and differentiate toward desired lineages. For example, several engineering techniques have been developed to obtain nanofibrous scaffolds and nano-topographical surface to control over the stem cell proliferation, migration and differentiation (Fig. 1). In short, a range of multifunctional NMs for stem cell therapy applications have been developed and investigated over the past few decades. However, most of the research has focused on the development of novel methods to fabricate nanoparticles for stem cell imaging and therapy, ${ }^{18-21}$ the interactions between nanomaterials and stem cells are not completely understood.

Accumulating evidence presents that nanomaterials (NMs) have the potential to influence stem cell function due to their small size and bioactive characteristics., ${ }^{4,22}$ Recently, aqueous suspension nanoparticles (NPs) have also been demonstrated to own the capability to induce stem cell specific differentiation, although the chemical origins of these may be complex ${ }^{23}$ (Fig. 2). For instance, silicate NPs, carbon nanotubes and gold NPs could promote osteogenic differentiation of mesenchymal stem cells (MSCs) in the absence of other inductive agents. ${ }^{23-26}$ Therefore, it is very important to carefully characterize the interactions between stem cells and NMs, particularly the differential potential influenced by NMs. In fact, the process of interactions between NP and stem cells is dynamic and complex. Asides from that, differentiation of stem cells influenced by NPs is often obscure and requires long time to observe. In view of this, it is essential to explore the impacts of NPs on differentiation of stem cells from not only a nanotoxicological but also a therapeutic viewpoint before nanotechnology can be fully applied to stem cell therapy.

\section{(a) Stem cell interaction with nano-structure scaffolds}

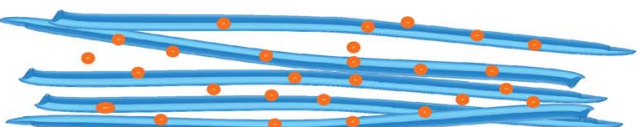

Oriented
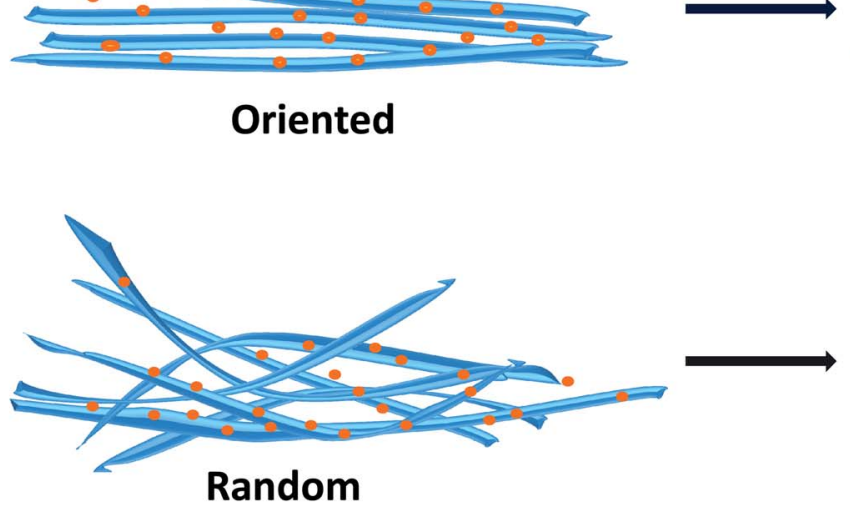

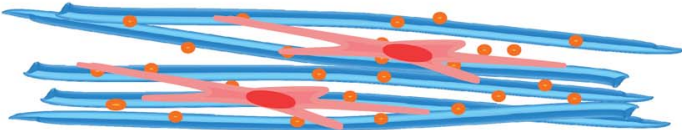

(b) Nanopatterned surface to mediate stem cell
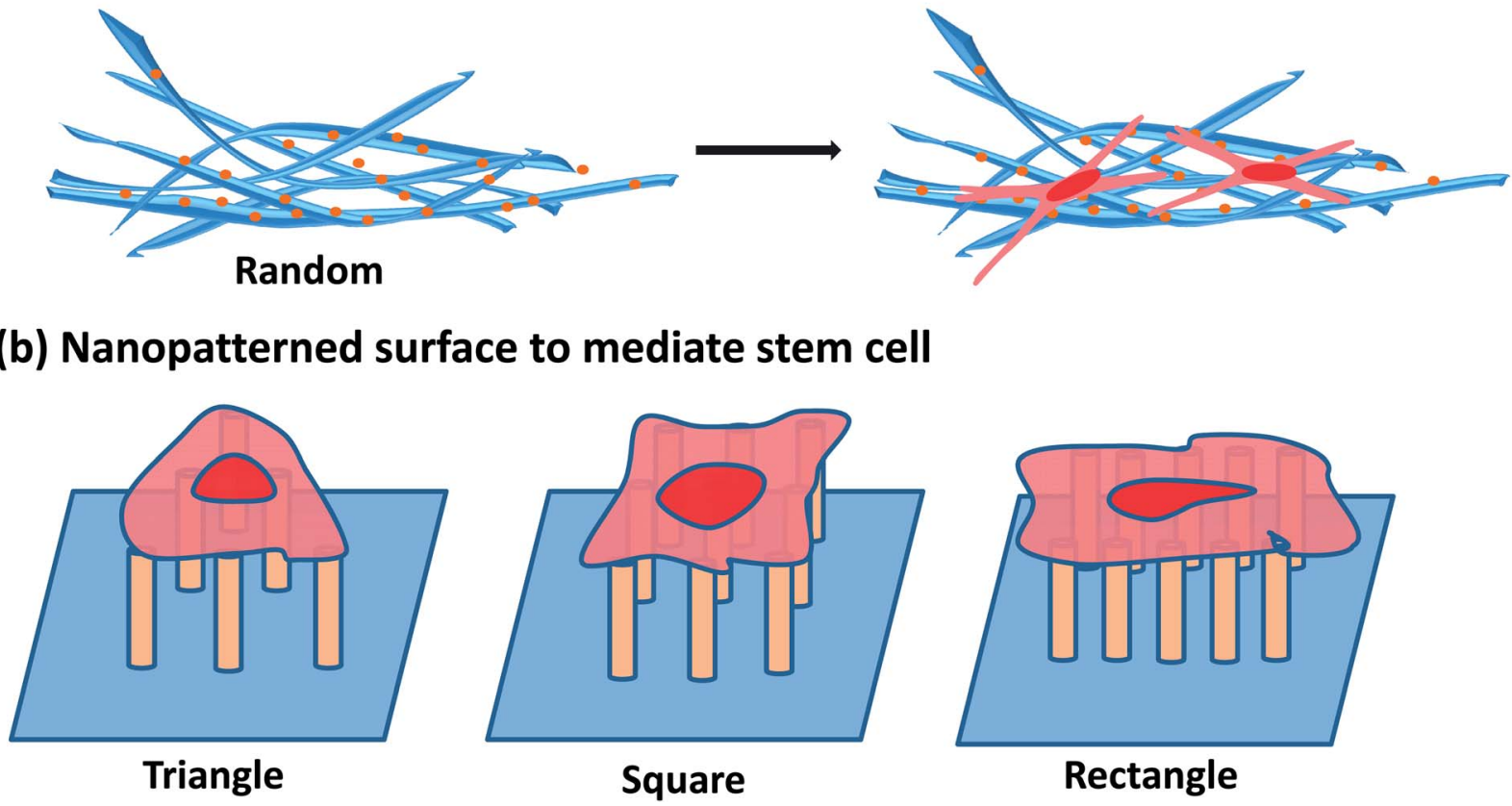

quare

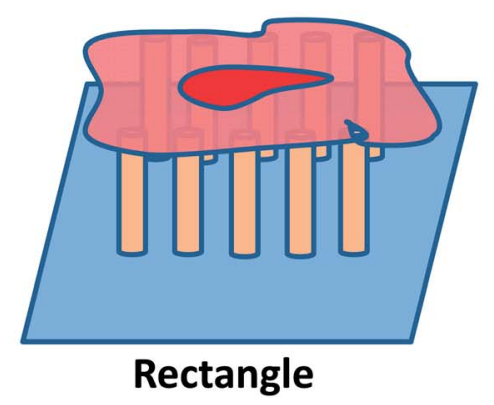

Fig. 1 The interaction of stem cells with various nanotopographical surface. (a) Stem cells interaction with nanostructure scaffolds. (b) Nanopatterned surface to mediate stem cells behaviors. 
Soft NMs
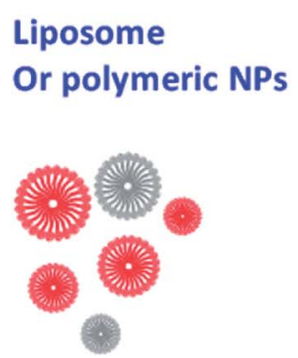

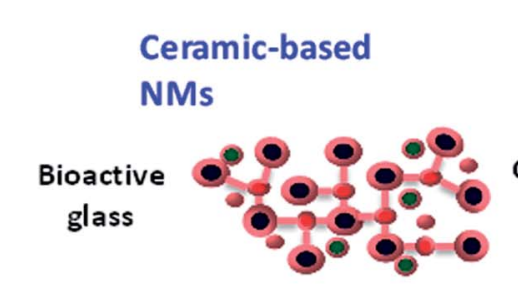

Hydroxyapatite
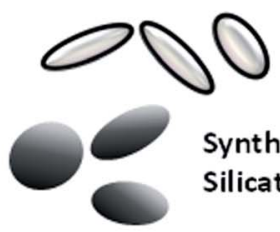

Synthetic Silicates

\section{Hard NMs}
Metal/Metal-oxide
NMs
NMs

Graphene
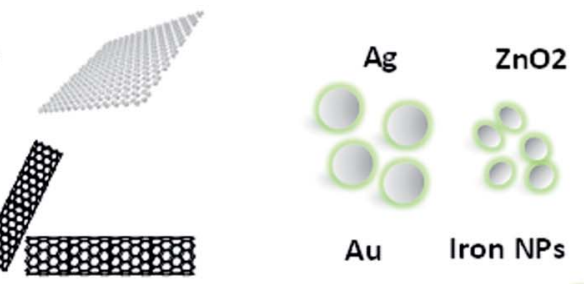

Au Iron NPs

CNTs

将

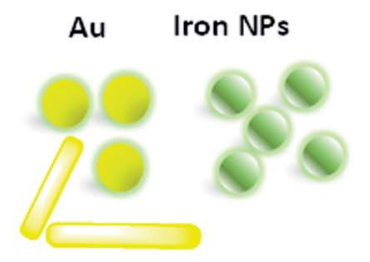

Diamond
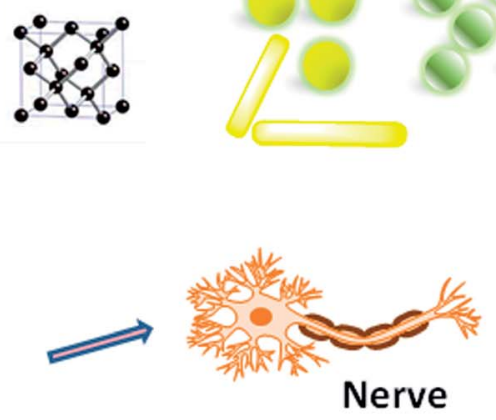

Bone
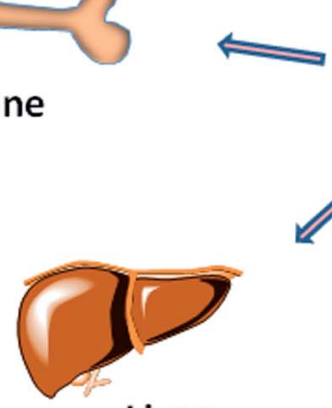

Liver
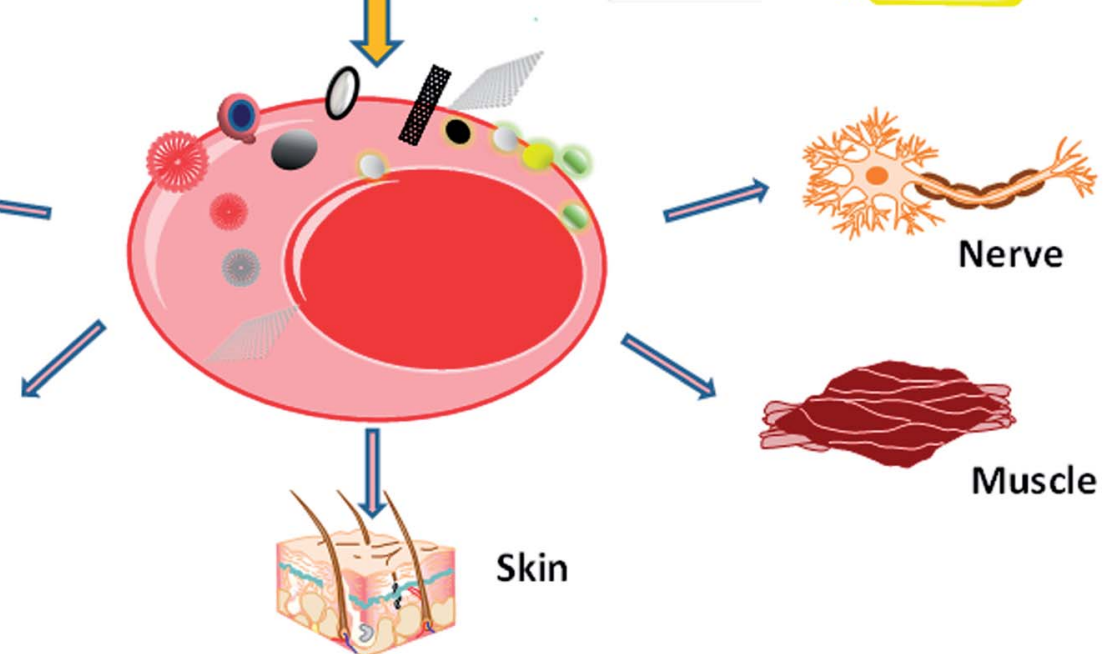

Fig. 2 Schematic illustration of nanomaterial interactions with stem cells. These interactions can stimulate the differentiation of stem cells to a variety of tissues including but not limited to nerve, muscle, skin, liver and bone.

The current review will provide a clear overview of the interactions between NPs and stem cells, especially focusing on the effects of NPs on toxicity and differentiation of stem cells. Firstly, we will systematically discuss the different components of the NP and the evidence that affects stem cell toxicity and differentiation. Subsequently, we will explore the biological mechanisms of cell differentiation induced by NPs. Finally, the future perspective and challenge of NPs for stem cell engineering are discussed. It is anticipated that the enhanced understanding of NP-stem cell interactions will be beneficial in designing the next generation of clinical therapies.

\section{Stem cells}

Stem cells are unspecialized cells, which possess the capability to renew themselves without obvious changes in their general properties. They can differentiate into a range of specialized cell types under certain conditions. As described above, the stem cells are mainly classified into three types: embryonic stem cells (ESCs) and adult (somatic) stem cells
(ASCs) and induced pluripotent stem cells (iPSCs). The following sections will introduce the three types of stem cell systematically.

\subsection{Adult stem cells}

Although be found in tissues nearly all over the body, while the mostly used ASCs are generally derived from bone marrow and adipose tissue. ${ }^{27}$ These cells play important roles in regenerating/repairing damaged tissue. Recently, ASCs have been used to treat several diseases, such as leukaemia and related bone and blood cancers through bone marrow transplants. Mesenchymal stem cells (MSCs) and hematopoietic stem cells (HSCs) are the two most common types of ASCs. MSCs as the multipotent stromal cells can be differentiated into several cell types, such as osteoblasts, chondrocytes, myocytes, adipocytes and hepatocytes. The HSCs as another type of bestcharacterized ASCs have great potential for stem cell therapy due to their effective self-renewal and differentiation ability. HSCs reside mainly in bone marrow, and niches are associated with either bone surfaces or sinusoidal endothelium. ${ }^{28}$ 


\subsection{Embryonic stem cells}

ESCs are the prototypical stem cells, and unambiguously fulfill all requirements of stem cells, such as clonality, self-renewal and multipotentiality. Since ESCs own the ability to differentiate into any cell present in the adult organism, they are considered as a potential source for regenerative medicine and tissue replacement. However, apart from ethics problems, immunological rejection and teratomas formation limit the therapeutic use of ESCs in vivo.

\subsection{Induced pluripotent stem cells}

Pluripotent stem cells (PSCs) are a unique model for studying the processes that occur in the early development of mammals and a promising tool in cell therapy of human diseases. ${ }^{29}$ The unique nature of these cells lies in their capability of unlimited self-renewal and reproduction of all adult cell types in the course of their differentiation. ${ }^{30}$ Induced pluripotent stem cells (iPSCs) are a new type of PSCs that can be obtained by reprogramming animal or human differentiated cells. iPSCs are considered as the PSCs derived from somatic ones, which closely resemble ESCs in a broad spectrum of features, such as similar morphologies, growth manners and equally sensitive to growth factors/signaling molecules. Additionally, similar ESCs, iPSCs can differentiate into derivatives of all three primary germ layers (ectoderm, mesoderm, and endoderm) in vitro and form teratomas following their subcutaneous injection into immune deficient mice. Murine iPSCs injected into blastocysts are normally included in the development to yield animals with a high degree of chimerism. Moreover, when injected into tetraploid blastocysts, murine iPSCs can develop into a whole organism. $^{31,32}$ Thus, strategies that allow the preparation of iPSCs from various somatic cell types while bypassing ethical problems have been uncovered by researchers. Nonetheless, the safe application of iPSC-based therapy requires the use of methods of iPSCs production and their directed differentiation which minimize both the possibility of mutations in cell genomes under in vitro culturing and the probability of malignant transformation of the injected cells. Moreover, it is necessary to find a way for human iPSC culturing without the use of animal cells; the way makes a viral-origin pathogen transfer from animals to humans impossible. Therefore, the maximum standardization of conditions for cell culturing and differentiation is urgently required.

\section{Nanomaterials}

Exploration of NMs in stem-cell applications is remarkably increasing, where a lot of efforts have been put in the fine design and tuning of new materials. ${ }^{\mathbf{4 3 3 , 3 4}}$ Currently, the number of NM-based agents undergoing clinical trials is increasing. ${ }^{35}$ However, due to the lack of understanding in the potential danger of NMs and appropriate legislation, nanotechnology industry is facing significant hardness in their attempt to fulfill NMs in a clinical setting. ${ }^{36,37}$ The clinical implementation differs between soft NMs (lipid- or polymer-based) and hard NMs (metal- or silica- or ceramic-based). The various types of
NPs currently applied or explored for stem-cell-therapy will be discussed briefly in this section. We will focus on introducing the different types of NMs, a short description of their important properties, and overview of their current or potential future applications in stem-cell-therapy.

\subsection{Clinical use of nanomaterials in stem cell therapy}

Stem-cell therapy is the use of stem cells to cure or prevent a disease. Stem cells are of great promise for treatment of many debilitating diseases owing to their great potential capacity to regenerate or stimulate the regeneration of diseased host tissue. Clinical trials are currently under way to explore the use of stem cells for the treatment of several diseases including Crohn's disease, diabetes, bone defects, myocardial infarction, stroke, etc. Despite its potential, stem cell therapy is limited by the substantial risks of malignant transformation of transplanted cells. Thus, there is still much to be studied about stem-cellbased approaches. One important aspect in stem cell therapy is to identify transplantable cells that are able to survive, integrate with the host tissue, and undertake the desired cellular differentiation. To address these questions, noninvasive cellular imaging is currently a very active field of clinic research. Clinically, imaging technologies such as optical, photoacoustic, magnetic resonance imaging (MRI), X-ray computed tomography (CT scans) and plain radiography (radioisotope imaging) are employed for this purpose. Stem cell imaging using these technologies usually involves the labeling of the cells with a probe or contrast agent that allows them to be distinguished from the host cells.

Relative to the bulk counterparts, NPs possess several unique properties, such as surface-to-volume ratio $(S / V)$, high surface energy, distinctive mechanical, thermal, electrical, magnetic, and optical behaviors. ${ }^{38,39}$ In addition, with advancements in synthetic and modification methodologies, NPs can be fabricated to desired sizes, shapes, compositions and properties. ${ }^{\mathbf{4 0 , 4 1}}$ Moreover, through combined methodologies from bioorganic/ bioinorganic and surface chemistry, multiple functionalized NPs can be achieved. These advantages give a strong signal, offer a direct and clear cell labeling, and allow noninvasive in vivo scanning. ${ }^{\mathbf{4 2 , 4 3}} \mathrm{Up}$ to present, NPs including quantum dots (QDs), magnetic nanoparticles (MNPs) and others can be harnessed to imaging and tracing of stem cells. ${ }^{44-47}$ Inorganic NPs, especially iron oxide NPs is one of the most promising materials for stem cell research because they can be synthesized easily in large quantities using relatively simple methods. ${ }^{48}$ Superparamagnetic iron oxide nanoparticle (SPION) core normally consists of ferromagnetic magnetite $\left(\mathrm{Fe}_{3} \mathrm{O}_{4}\right)$ and magnetite $\left(\mathrm{Fe}_{2} \mathrm{O}_{3}\right)$, and generally combinations with a polymer coating layer (e.g., dextran, carboxydextran, chitosan, gelatin, polyethylene glycol and polystyrene) that stabilizes the magnetic core. ${ }^{49}$ SPIONs have been used as magnetic resonance imaging (MRI) T-2 contrast agents since 1990, enhancing the contrast between tissues, ${ }^{50}$ providing more reliable methods of locating and tracking the transplanted cells. An ultrasmall SPION (ferumoxytol) originally approved by the US Food and Drug Administration (FDA) had been applied for cell labeling. ${ }^{\mathbf{1 1}}$ 
Castaneda et al. described a protocol for enhancing signal intensity for MRI by using ferumoxytol and protamine to label human mesenchymal stem cells, human embryonic kidney 293 cells, and induced pluripotent stem cells. ${ }^{52}$ Furthermore, another clinical study was published using MRI to track cells in vivo. Autologous mesenchymal stem cells (MSCs) were injected intravenously into 15 patients in Israel with Multiple Sclerosis (MS) and 19 patients with Amyotrophic Lateral Sclerosis (ALS). Using SPION labeling for MRI, researchers in this study were able to assess both the safety and feasibility of stem cell transplantation in MS and ALS patients and found no incidences of significant adverse effects. ${ }^{53}$

Due to the unique characteristics of stem cells, namely selfrenewal and differentiation potential, stem cell therapy has become one of the fastest growing fields of research in the world. Several adult stem cells, progenitor cells, and induced pluripotent stem cells (iPSCs) have since been isolated and characterized with respect to their potential clinical benefit to treat cardiac diseases, superficial wounds, neurologic diseases, and type I diabetes. ${ }^{54-57}$ Transplanted stem cells can rebuild or replace dead tissues and recover existing cells through paracrine effects. However, the stem cell differentiation process in most cases is still necessarily heterogeneous, of which uniformity is critical for preventing tumorigenic potential. The activation of an immune response along with an otherwise inhospitable host environment results in a low viability for the majority of transplanted cells. ${ }^{58}$ Many research groups have addressed these problems through the development of intracellular delivery of functional molecules, such as DNA, RNAi, peptides, proteins, and drugs that control the stem cell behaviors and fates. ${ }^{54,59}$

Some of the drug/chemicals have poor solubility, short halflife and/or poor penetration into cells. Moreover, naked nucleic acids cannot successfully enter cells which require the assistance of a suitable vector. ${ }^{60,61}$ Once inside in the cells, exogenous nucleic acids can be quickly degraded by intracellular enzymes. ${ }^{60}$ Since their unparalleled advantages, NPs have shown great potential as intracellular nanocarriers for drug/ nucleic acid delivery in the differentiation of stem cells. ${ }^{62}$ Moreover, NPs can be functionalized to target stem cells and release their payloads in the cytoplasm. ${ }^{63-66}$ Combination of nanomaterials and stem cells brings us powerful tools to generate various specific lineages like osteoblast, neural cell, cardiocytes, chondrocyte, hepatocyte-like cells and so on. For example, silica NPs can be designed as nanocarrier to carry insulin to rat MSCs for adipogenic differentiation modulation ${ }^{67}$ or delivery ascorbic acid to human embryonic stem cells (hMSCs) for cardiac differentiation stimulation. ${ }^{68}$ In addition, the nanoscale lipoplex particles formed by the spontaneous assembly of DNA and cationic liposomes are mostly used for gene transfection or lipofection. Lipofectamine 2000, a commercially available lipoplex complex, successfully delivered fork head box A2 (Foxa2) gene into MSCs to enhance damaged liver tissue regeneration. ${ }^{69}$

However, there are still some apparent challenges in thusproduced NPs to clinical applications: (1) it is likely that true stem cell tracking through single imaging modality was not enough. Upon implantation, the problem of knowing whether one is imaging implanted stem cells or host tissue existed, as the evidence suggesting that contrast agents can be transferred from the dead stem cells to host cells, which generating false positives. Thus, it will be of significant value to develop hierarchical NP probes functionalized as multiple contrast agents for simultaneous use under various imaging modalities including optical, magnetic resonance (MR), positron emission tomography (PET), single photon emission computed tomography (SPECT) and computed tomography (CT) imaging. These integrated imaging can provide comprehensive information for accurate diagnosis in a reduced time. (2) Since the most of the NPs applied in stem cell therapy are not biodegradable, their long-term biological safety, chronic toxicity and other side effects should be noted. (3) As the evidence showing that NPs themselves play a role in stem cell differentiation, it is important to allow committed differentiation of stem cells into specific lineage.

\subsection{Soft nanomaterials}

Soft NMs are built from molecular blocks, and generally can be considered as lipid- and polymer-based materials at a nanoscale feature. ${ }^{70}$ Over the past few decades, the soft NMs are used as carriers to load or encapsulate drug/gene for stem-cellmodulating or tracking. ${ }^{71}$ However, their potential effects on stem cell (e.g., cellular uptake, toxicity and differentiation) are largely overlooked.

3.2.1 Lipid-based NPs. Lipid-based NMs are generally organized into liposomal structures, originally discovered by Bangham and colleagues in $1965 .{ }^{72,73}$ The principal applications of liposomes in stem-cell-therapy lie in their use as vehicles for promoting delivery inducing or imaging agents through enclosing within its aqueous central cavity (for hydrophilic agents) or embedded within the lipid layers (for hydrophobic agents). ${ }^{74-77}$ For example, recently, a bioreducible lipid NP was developed for miRNA delivery to hMSCs. $^{78}$ It was demonstrated that miR-9 molecules were successfully delivered into hMSCs, and could induce a change in the morphology of hMSCs and high neuronal marker gene expression in the cells. Moreover, the differentiated hMSCs could be applied for the treatment of nerve injuries and neurodegenerative diseases. ${ }^{78}$ Moreover, the lipids are also used as a coating layer. For example, paramagnetic Gd-diethylene triamine pentaacetic aciddi(stearylamide) (Gd-DTPA-DSA) and poly(ethylene glycol) containing 1,2-distearoyl-sn-glycero-3-phosphoethanolamine- $N$ [methoxy(poly(ethylene glycol))-2000] (PEG-DSPE) lipids are applied to coat the hydrophobic QD@SiO ${ }_{2}$ nanoparticles with a monolayer of lipids. This nanomaterial platform serves as a bioapplicable, multimodal contrast agent for MR and fluorescence imaging. ${ }^{79}$ Hsieh et al. demonstrated that, through liposome-mediated transfection, hBMSCs could br efficiently labeled with CdSe/ZnS QDs. Additionally, internalization of QDs into hBMSCs had no significant influence on their proliferation, while inhibited osteogenic differentiation. ${ }^{\mathbf{8 0 , 8 1}}$

With its similar components to cellular membrane and low mechanical properties, it seems that the effect of liposomes on 
stem cell behaviors is negligible. Therefore, the effects of lipidbased NPs itself on stem cell behaviors are poorly studied. More recently, Chabra et al. observed that solid lipid NPs could regulate functional assortment of mouse mesenchymal stem cells. $^{82}$ Jung et al. reported that glycosphingo lipids were involved in the proliferation of mESCs through ERK1/2 activation, and played important regulatory roles in proliferation and differentiation of neural precursor cells derived from mESCs. ${ }^{83}$ Moreover, some bioactive lipid, such as sphingosine-1phosphate, can regulate diverse biological processes including cell growth, cell survival, cell migration and cell differentiation. ${ }^{78}$ These studies highlight that the lipid-based NP itself has a high potential to affect the stem cell differentiation.

3.2.2 Polymeric NPs. Polymers are macromolecules, composed of a number of repeated subunits, and play an essential and ubiquitous role in biological life. Polymers are mainly divided into two categories: synthetic and natural polymers. Synthetic polymers such as poly(lactide-glycolide) copolymers, such as polycaprolactones (PCL), poly(lactic-co-glycolic acid) (PLGA), and polyesters including polylactide (PLA). Protein, DNA, peptide, chitosan, hyaluronic acid and alginate are examples of natural polymers. The polymeric NPs are widely used in stem cell therapies due to their excellent biocompatibility and low immune reactivity. The most widely used application of polymeric NPs in stem cell therapy is the encapsulation or immobilization of bioactive factors or genes inside the stem cells to protect them from degradation by enzymes and significantly decrease their consumption (up to $10^{4}$-fold less). ${ }^{75,84}$ For this purpose, polymers are typically cationic and interact with negatively charged nucleic acids or growth factors through electrostatic force, which condense them into particles to several hundred nanometers in diameter. For example, Kim et al. reported that polyplexing with polyethylenimine (PEI) onto PLGA NPs enhanced the cellular uptake of SOX9 DNA both in vitro and in vivo, allowed robust gene expression in human mesenchymal stem cells (hMSCs), and induced chondrogenesis. ${ }^{85}$ Treatment of PLGA NPs with positively charged PEI complexed to negatively charged DNA results in the spontaneous electrostatic formation of stable NP complexes. Moreover, PEI-modified PLGA NPs interacted with the negatively charged lipid bilayers of cell membrane, and entered into endosomes, released of the transfected genes into the cytoplasm. Besides, PEI-modified PLGA NPs used as gene carriers for exogenous SOX trio (SOX5, 6 and 9) induced a significant increase in the chondrogenesis of hMSCs in vitro culture. $^{86}$ Other polymers including poly $(\mathrm{N}$-isopropylacrylamide) (PNIPAm), palmitic acid and PLGA and their complexes, have been applied for growth factor or gene delivery. Recently, the nanocarriers of PLGA and PNIPAm achieved a gradual release of insulin-like growth factor I (IGF-I) and transforming growth factor $\beta 1$ (TGF- $\beta 1$ ), supported by chondrogenesis in MSCs. ${ }^{87}$ Apart from the above synthetic polymeric NPs, the natural polymer based NPs have been widely used as nanocarriers in stem cell therapy. ${ }^{\mathbf{8 8 - 9 0}}$ Suja Shrestha et al. fabricated a chitosan NP system with temporal-controlled dexamethasone releasing properties, which could enhance odontogenic differentiation of stem cells from apical papilla obviously. ${ }^{89}$ S. Pulavendran et al. developed a hepatocyte growth factor (HGF) loaded chitosan NP, showing sustainable release of HGF, which could differentiate MSC into hepatocytes. ${ }^{91}$ Chitosan was also modified with cationic etherifying agent to obtain the CS derivative as the gene delivery nanocarriers. Guang-Feng Li et al. synthesized a $N$-2-hydroxypropyl trimethyl ammonium chloride chitosan (HACC), and successfully used as gene delivery vehicles for MSC lines. ${ }^{\mathbf{9 0}}$ Moreover, the combination of natural polymer with synthetic polymer-related NPs could increase compatibility and gene delivery efficiency. ${ }^{92}$ It was observed that chitosan/tripolyphosphate/HA NPs successfully delivered the anti-miRNA-138 inside cells, and enhanced osteogenic differentiation of MSCs. ${ }^{93}$ Dexamethasone (Dex) loaded carboxymethylchitosan/poly(amidoamine) dendrimer NPs enhanced osteogenic differentiation of rat bone marrow stromal cells. ${ }^{94}$ The dexamethasone loaded carboxymethyl chitosan/poly(amidoamine) dendrimer nanoparticles could enhance osteogenic differentiation of MSCs, both in vitro and in vivo. ${ }^{95-97}$

In addition, the polymer-based NPs can load the diagnostic or imaging agents to track/image the stem cells. For example, the fluorescent tags linked $\mathrm{N}$-isopropylacrylamide-based thermoresponsive nanogels were successfully applied in tracking NSCs from the postnatal subventricular zone, and without affecting their proliferation, multipotency and differentiation characteristics. ${ }^{98}$ This study also reported an increase in the number of neurons when the nanogels were loaded with retinoic acid, improving the solubility of the drug and its release behavior. ${ }^{98}$ Chen developed a near-infrared (NIR) fluorescent semiconductor polymer dot for bright labeling and tracking of MSCs. ${ }^{99}$ The polymer dots exhibit narrow-band emission at $775 \mathrm{~nm}$ with a quantum yield of $22 \%$, among the highest value for the current NIR probes. The polymer dots together with a cell penetrating peptide were able to track stem cells over two weeks without disturbing their multipotent properties. Furthermore, the in vivo cell tracking was demonstrated in a liver-resection mouse model, which indicated that the polymer dots-labeled MSCs after tail-vein transplantation were initially trapped in lung, gradually migrated to the injured liver, and then proliferated into cell clusters. Liver-function analysis and histological examination revealed that the inflammation induced by liver resection was apparently decreased after stem cell transplantation. Considering their bright labeling, superior biocompatibility, and long-term tracking performance, the polymer-based probes are promising for stem cell imaging.

Although the application of polymeric NPs as carriers for stem cells therapy or imaging has gained great interest and success, the potential impact of polymeric NPs themselves on stem cell behaviors is far from being completely researched. Recently, Laura Florez et al. prepared fluorescent prolate polymeric NPs with different aspect ratios by stretching spherical NPs, and investigated the interactions between NPs with MSCs. ${ }^{100}$ Non-spherical particles exhibited less uptake by MSCs than their spherical counterparts with a negative correlation between aspect ratio and uptake rate. ${ }^{\mathbf{1 0 0}}$ Jiang et al. prepared two types of NPs, plain polystyrene (PS) NPs and amino-functionalized polystyrene NPs (NPS). Using a similar 
zeta potential and size, they investigated the effects of surface amines on PS NPs on their interactions with MSCs. ${ }^{101}$ NPS NPs were rapidly internalized and accumulated to a much higher level in MSCs than PS NPs, mainly via clathrin-mediated pathway. PS NPs were internalized via clathrin-independent endocytosis. These cellular uptake behavior differences of PS and NPS were largely owing to the specific interactions of the amino groups on the NPs with the endocytosis machinery of MSCs. ${ }^{101}$ Interaction with polymeric particles may change the structure and function of the cytoskeleton, and influence cell shape and signal pathways, and thereby modulate the differentiation of stem cells. More recently, bovine serum albumincoated poly(lactic-co-glycolic acid) particles (PLGA-BSA) were prepared and their interactions with MSCs were systematically studied (Fig. 3). ${ }^{\mathbf{1 0 2}}$ The PLGA-BSA particles were largely internalized, and promoted osteogenic alkaline phosphatase (ALP) activity and enhanced the expression of collagen type I (COL I) and osteocalcin (OCN) of MSCs. Moreover, the internalized PLGA-BSA particles inhibited the expression of adipogenic peroxisome proliferator-activated receptor-gamma (PPAR $\gamma$ ) and lipoprotein lipase (LPL) at both mRNA and protein levels. ${ }^{102}$ Shu Huang et al. observed that chitosan/hyaluronic acid (CS/HA) NPs could promote chondrogenic outcome while preventing the inflammatory status of ACs and the hypertrophic differentiation of MSCs. ${ }^{103}$ Besides the conventional NP, the DNA nanostructures were also reported to influence the stem cell differentiation. Wenjuan Ma et al. observed that tetrahedral DNA nanostructures (TDNs) treatment promoted the self-renew of the stem cells via activating the Wnt/ $\beta$-catenin pathway and inhibiting the Notch signaling pathway. ${ }^{104}$ Moreover, TDNs could enhance osteogenic differentiation and proliferation of adipose-derived stem cells (ADSCs) via activating Wnt/ $\beta$-catenin pathway. ${ }^{105}$

Overall, polymeric NPs have been demonstrated to possess enormous potential application in stem-cell-therapy. So far, understanding the effects of the pristine polymeric NP and its degradation products on stem cell behaviors is largely limited. Nevertheless, engineering multifunctional sections of delivery systems, for instance, dual/sequential delivery, and specifictargeting for combinatorial effects would provide great flexibility in polymeric NPs design for stem-cell-therapy particular application.

\subsection{Hard nanomaterials}

Hard NMs are generally inorganic nanocrystals, and represent a wide variety of compounds, including ceramic-, carbon-, and metal-/metal oxide-based materials. ${ }^{106}$ These hard NMs own various unique properties in comparison with their bulk counterparts as the result of their nanoscale size. ${ }^{\mathbf{1 0 7 , 1 0 8}}$ Examples of such unique properties include the superparamagnetic nature of iron oxide NPs, ${ }^{\mathbf{1 0 9}}$ high quantum yield and excellent
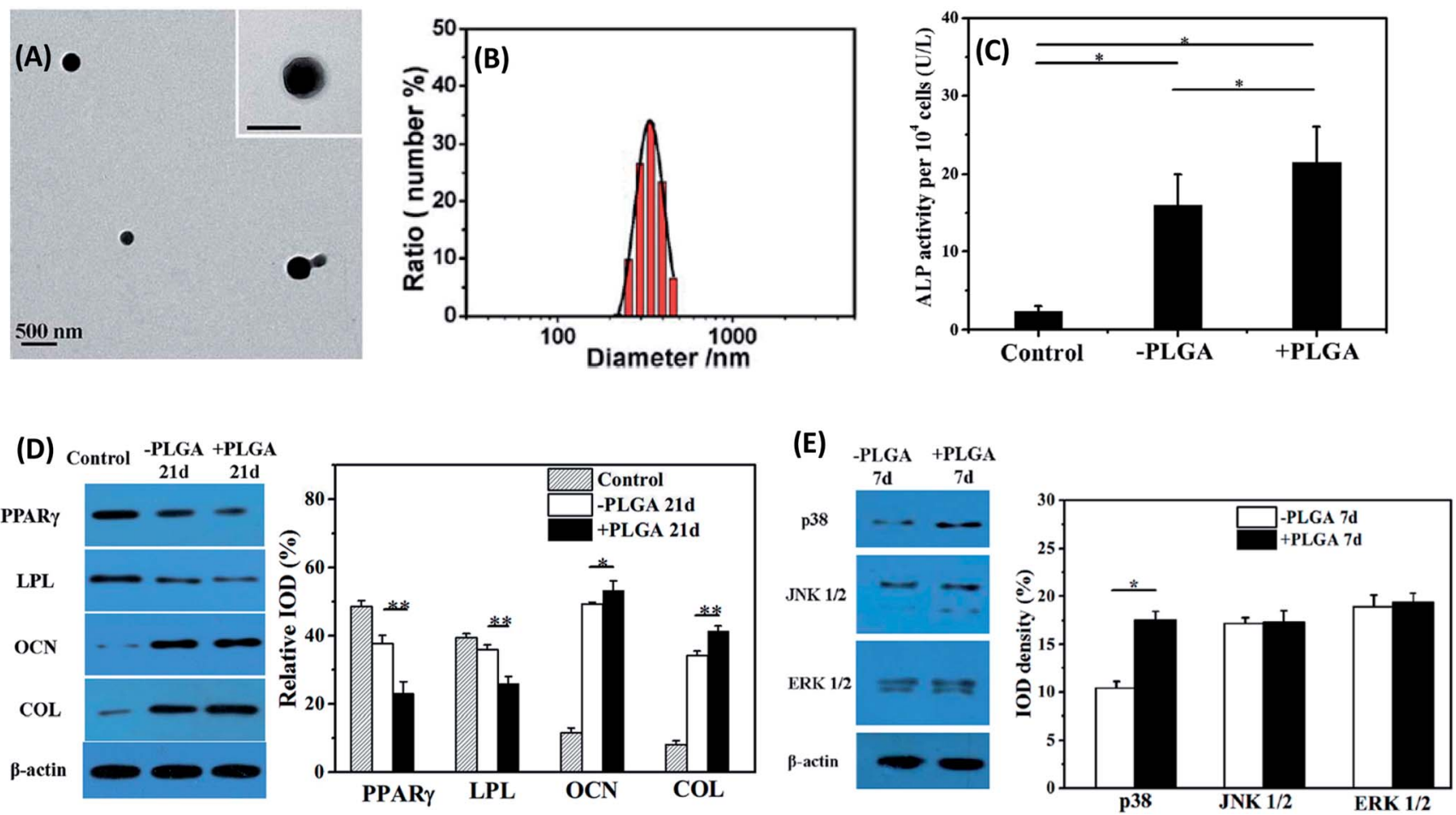

Fig. 3 Representative TEM images (A) and size distribution histogram (B) of PLGA-BSA particles. (C) ALP activity of pristine MSCs (control), MSCs cultured in particle-free medium for $7 \mathrm{~d}$ (-PLGA) and PLGA-BSA particles for $7 \mathrm{~d}$ (+PLGA). (D) Western blot analysis of osteogenic markers (OCN and $\mathrm{COL}$ ) and adipogenic markers (PPARg and LPL) expressed by pristine MSCs (control), MSCs cultured in particle-free medium for $21 \mathrm{~d}(-\mathrm{PLGA})$ and PLGA-BSA particles for $21 \mathrm{~d}$ (+PLGA) (E) western blot analysis of MAPK pathway related proteins (p38, JNK1/2, ERK1/2) expressed by pristine MSCs (control), MSCs cultured in particle-free medium for $7 \mathrm{~d}$ (-PLGA) and PLGA-BSA particles for $7 \mathrm{~d}$ (+PLGA). The particle concentration used here was $50 \mu \mathrm{g} \mathrm{mL}^{-1}$. $*$ and ** indicate significant difference at $p<0.05$ and $p<0.01$ levels, respectively. Reproduced with permission. ${ }^{102}$ Copyright 2015, Royal Society of Chemistry. 
photostability of quantum dots (QDs) ${ }^{110}$ high rigidity of carbon nanotubes ${ }^{111}$ and so on. In view of these exciting properties, hard NMs have obtained great interests in biomedical applications. Similar to the soft NMs, conjugation of drugs/genes or fluorescence agents to these hard NMs also has broaden their applications. Furthermore, the pristine hard NMs were often reported to have a significant impact on the stem cell behaviors, and may present great potential to be used as a modulator to mediate stem cell differentiation.

3.3.1 Ceramic-based NMs. Because of their bioactive characteristics, bioactive nanoceramics such as bioactive glasses (BG), nanosilicates, hydroxyapatite (HAP) and silica nanoparticles (SiNPs) have been widely used for tissue engineering and regenerative medicine. Since its similarity with bone components, it was demonstrated in a number of studies that stem cells could be able to recognize the chemical structure of the bioactive nanoceramics and promote osteogenic differentiation on its surface. Nevertheless, the effects of NMs inside the cells on stem cell behaviors are largely different from that on their surface. A number of studies have explored the possible cellular toxicity and differential potential induced by ceramicbased NMs. Recently, sub-micron particles of bioactive glass (SMBGs, $\sim 250 \mathrm{~nm}$ ) composed of $85 \mathrm{~mol} \% \mathrm{SiO}_{2}$ and $15 \mathrm{~mol} \%$ $\mathrm{CaO}$ were synthesized, and the flowed effects of the exposure of SMBGs $\left(100 \mu \mathrm{g} \mathrm{mL} L^{-1}, 150 \mu \mathrm{gL}^{-1}, 200 \mu \mathrm{g} \mathrm{mL}^{-1}\right)$ to hMSCs on cell viability, metabolic activity and proliferation were examined. ${ }^{112}$ Cytotoxicity of all the SMBGs was dose-variant and timedependent. All of the SMBG concentrations caused no significant cytotoxicity at 1 and 4 days, but the doses of 150 and $200 \mu \mathrm{g}$ $\mathrm{mL}^{-1}$ significantly decreased hMSC metabolic activity after 7 days of co-culture. ${ }^{112}$ Subsequently, the viability and differentiation potential of MSCs and adipose-derived stem cells (ADSCs) induced by spherical monodispersed bioactive glass particles (mono-SMBG, size: $215 \pm 20 \mathrm{~nm}$ ) were evaluated. ${ }^{113}$ The monoSMBGs did not have obvious effect on metabolic activity and osteogenic differentiation potential of MSC or ADSC at the test concentration $\left(50 \mu \mathrm{g} \mathrm{mL}{ }^{-1}\right) .{ }^{113}$ Moreover, the hydroxyapatite (HAP) NP-induced stem cell behaviors including cellular cytotoxicity and differential potential were assessed. Then, the hydroxyapatite (HAP) NPs with different surface charges were synthesized and their interactions with MC3T3-E1 cells (osteoblast) were investigated. ${ }^{114}$ As a result of attractive force, positively charged HAP NPs accelerated cellular uptake compared with negatively charged ones. ${ }^{114}$ In comparison with the control (cells without NP treatment), MC3T3-E1 cells treated with the HAP NPs enhanced cell viability and proliferation, regardless of their surface charge. More interestingly, among the three kinds of HAP NPs (neutral, positive and negative), positively charged HAP NPs showed the largest increased cell viability and proliferation. ${ }^{114}$ However, another work found that only a lower HAP NP concentration $\left(<20 \mu \mathrm{g} / 10^{4}\right.$ cells $)$ could promote the MSCs proliferation, higher particle concentrations $\left(>20 \mu \mathrm{g} / 10^{4}\right.$ cells $)$ significantly inhibited the cell growth. ${ }^{115}$ Eventually, the HAP NPs could enhance osteogenic differentiation of MSCs at all the test concentrations in the absence of any other inducing agents as evidenced by enhanced expression of collagen I. ${ }^{115}$
Besides, silica NMs as another type of ceramic-based NMs have been reported to possess the ability to mediate stem cell behaviors. Gaharwar et al. studied the effects of synthetic silicate nanoplatelets on cellular metabolism and human MSCs (hMSCs) differentiation (Fig. 4). ${ }^{116}$ Nanosilicate is a disc-shaped NM with an average-diameter of 20-30 nm and $1 \mathrm{~nm}$ thickness (Fig. 4A). After being incubated with hMSCs, silicates were quickly adhered to cell surface and internalized by hMSCs. The internalized amount of nanosilicates was dose-dependent, and ascended with the increase of NP concentration (Fig. 4B). At a lower concentration $\left(<100 \mu \mathrm{g} \mathrm{mL}^{-1}\right)$, the addition of nanosilicates did not significantly interrupt the metabolic activity of hMSCs. However, the metabolic activity of hMSCs dropped drastically at higher silicate concentrations $\left(>100 \mu \mathrm{g} \mathrm{mL}^{-1}\right)$. Half-maximum inhibitory concentration $\left(\mathrm{IC}_{50}\right)$ was observed to be $4 \mathrm{mg} \mathrm{mL}^{-1}$ (Fig. 4C). It is worth noting that, compared with the HAP NPs and SiNPs with a similar size, nanosilicates showed a certain cellular toxicity at a ten-fold higher concentration, indicating much more biocompatible. ${ }^{116}$ In addition, researchers also observed that the exposure of the nanosilicates to MSCs upregulated RUNX2, osteocalcin, osteopontin and mineralization in the absence of any inductive medium (Fig. 4D). Afterwards, the influence of different sizes of silica NPs on the proliferation of human adipose tissue-derived stem cells (hADSCs) was also studied. ${ }^{117}$ Silica NPs entered the cytosol through the cell membrane via endocytosis, and the internalized of silica NPs could accelerate cell growth. Moreover, silica NPs with a diameter of $50-120 \mathrm{~nm}$ were more effective in promoting cell growth by stimulating the ERK signaling pathway. ${ }^{117}$

3.3.2 Carbon-based NMs. Since the first discovery of carbon nanotubes (CNTs) in the early 1990s, carbon-based NMs (e.g., carbon nanotubes, graphene, and nanodiamonds) have gained increasing interests in biomedical applications owing to their unique structural, mechanical, electrical and thermal properties. Besides, another advantage is its ability to fabricate different shapes, structure and sizes with distinct properties. Given these exciting unique properties, carbon-based NMs are currently receiving great attentions in view of possible stem-celltherapy. Thus, an assessment of the interactions between carbon-based NPs and stem cells has acquired increment spotlights, especially to the guiding differentiation of stem cells.

(1) Carbon nanotubes. Carbon nanotubes (CNTs) are ordered thin and hollow cylinders, which were composed of carbon atoms bonded to each other via $\mathrm{sp}^{2}$ bonds, resulting in high mechanical strength, flexibility, thermal and electrical conductivity. Given their unique physicochemical properties, CNTs have strong potential for mediating stem cell behaviors. ${ }^{118}$ CNTs were often incorporated into scaffolds resulting in enhanced cell attachment, proliferation and differentiation. ${ }^{119}$ However, CNTs may be able to migrate through the cell wall to a nuclear location after $24 \mathrm{~h}$, and affect the following cell behaviors. ${ }^{120}$ The $\mathrm{COOH}$-functionalized single-walled carbon nanotube (SWCNT-COOH) was observed to own the ability to induce differentiation of MSCs along adipogenesis, osteogenesis, or chondrogenesis lines. ${ }^{120}$ Furthermore, SWCNT$\mathrm{COOH}$ could promote cell adhesion, spreading, and 
(A)

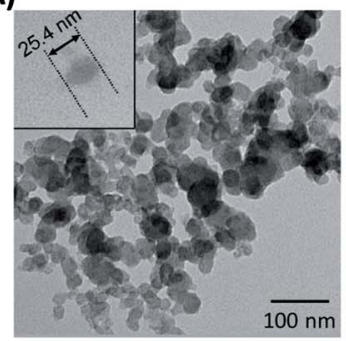

(D)
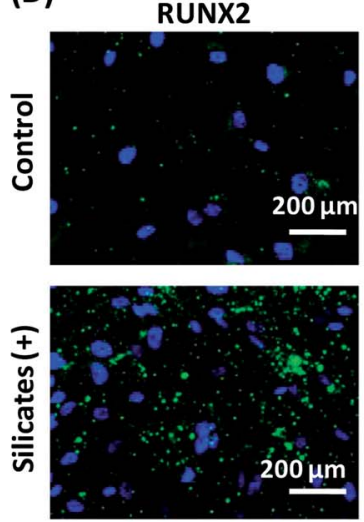

(B)

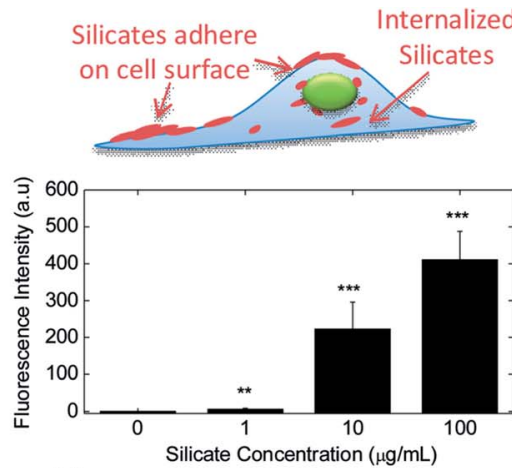

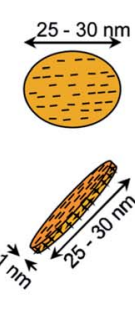

Osteocalcin
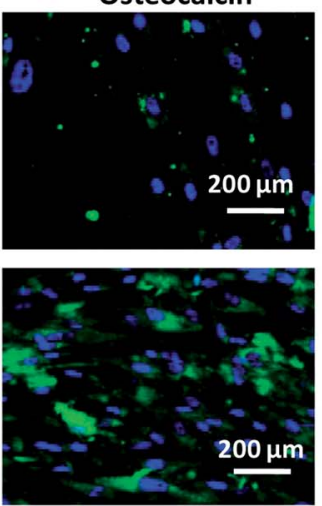

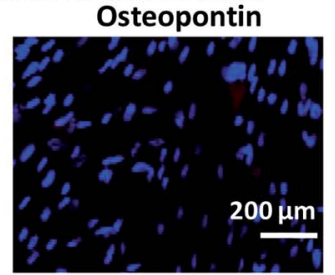

(C)

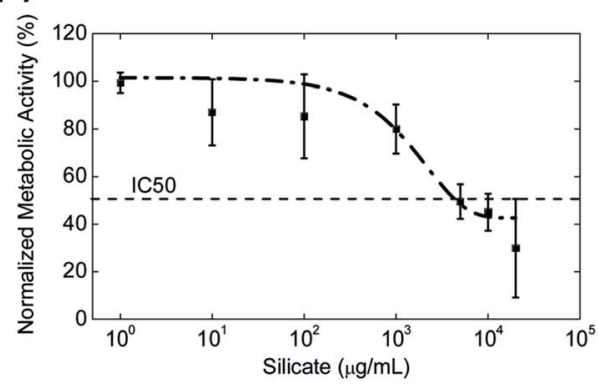

Mineralization

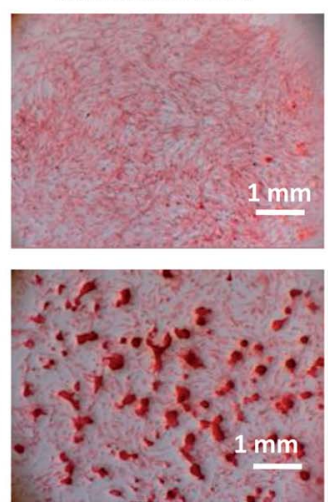

Fig. 4 Silicate nanoplatelets could induce osteogenic differentiation of stem cells in the absence of osteogenic factors. (A) TEM image of silicate nanoplatelets. The silicate nanoplatelets are disc shaped nanoparticle with $25.4 \mathrm{~nm}$ in diameter. (B) Cellular uptake of silicate nanoplatelets with different concentrations $\left(0,1,10\right.$ and $\left.100 \mu \mathrm{g} \mathrm{mL}^{-1}\right)$. (C) The metabolic activity of hMSCs in the presence of silicate nanoplatelets in the media at 48 hours of post seeding. The metabolic activity was normalized with the control (without NPs). The dotted line shows fitted dose response curve, and the $\mathrm{IC}_{50}$ was found at a silicate concentration of $4 \mathrm{mg} \mathrm{mL}^{-1}$. (D) Silicate nanoplatelets enhanced expression of RUNX2, osteopontin, osteocalcin, and matrix mineralization of MSCs incubated in normal growth medium. Reproduced with permission. ${ }^{116}$ Copyright 2013 , Wiley.

neurogenic differentiation of MSCs without any extra inducing agents. ${ }^{121}$ Additionally, the influence of the length of carboxylated multiwall carbon nanotubes (MWCNTs-COOH) on a neuronal-like model cell line PC12 cells was examined. ${ }^{122}$ The results showed that the MWCNTs-COOH did not significantly affect cellular morphology and viability at lower concentrations $\left(5 \mu \mathrm{g} \mathrm{mL}{ }^{-1}\right)$. Compared with the longer ones, the short MWCNTs-COOH enhanced cellular uptake efficiency and had stronger ability to promote PC12 cell differentiation. ${ }^{122}$ Moreover, the short MWCNTs-COOH exposure can up-regulate the expression of neurotrophin signaling pathway associated with TrkA/p75 receptors and pincher/Gap43/TH proteins, which may explain the underlying mechanism for the improved differentiation in PC12 cells. ${ }^{122}$ On the contrary, another study reported that both carboxylated single- and multi-walled carbon nanotubes (SWCNTs-COOH and MWCNTs-COOH) exhibited obvious cytotoxicity to MSCs, as evidenced by a decrease in cell viability even at the lowest dose $\left(3 \mu \mathrm{g} \mathrm{mL}{ }^{-1}\right) \cdot{ }^{123}$ In addition, CNTs-COOH could strongly inhibit both osteogenic and adipogenic differentiation probably due to their interaction with cell surface receptors or intracellular proteins, which activated a Smaddependent bone morphogenetic protein (BMP) signaling pathway. ${ }^{123}$ The ROS generation did not have any impact on the differentiation behaviors. ${ }^{123}$ In short, although CNTs seem to show positive roles in stem cell differentiation in the absence of other inducing factors, long term biological effects still need to be addressed.

(2) Graphene based NMs. Graphene (G) is a single-atomthick monolayer of $\mathrm{sp}^{2}$-bonded carbon atoms with a twodimensional honeycomb lattice structure. G-based NMs have many unique physicochemical properties, such as high surface area, extraordinary electrical and thermal conductivities, and strong mechanical strength. Given their excellent performance, G-based NMs have been widely used in stem-cell-therapy applications. This means that simultaneous detailed investigations about the interactions between G-based NMs and stem cells are urgently required. Recently, the size-dependent cytoand geno-toxic effects of the reduced graphene oxide nanosheets (rGONSs) on the hMSCs were investigated. ${ }^{124}$ After coculture with NPs and stem cells for $1 \mathrm{~h}$, it was observed that significant cell destructions caused by $1.0 \mu \mathrm{g} \mathrm{mL}^{-1}$ rGONSs with average lateral dimensions of $11 \mathrm{~nm}$, while the rGONSs with average lateral dimensions of $3.8 \mu \mathrm{m}$ could induce a significant cytotoxic effect only at high concentration of $100 \mu \mathrm{g} \mathrm{mL} \mathrm{m}^{-1}$. The rGONSs had genotoxic effects on the stem cells through DNA fragmentations and chromosomal aberrations, even at a low concentration of $0.1 \mu \mathrm{g} \mathrm{mL} .{ }^{124}$ Moreover, the genotoxicity effects of graphene nanoribbons (rGONRs) on hMSCs were also studied. ${ }^{125}$ Significant cellular toxic effects of $10 \mu \mathrm{g} \mathrm{mL}{ }^{-1}$ rGONRs were observed after $1 \mathrm{~h}$ exposure time. The rGONRs 
could penetrate inside the MSCs then cause DNA fragmentations as well as chromosomal aberrations, even at a low concentration of $1.0 \mu \mathrm{g} \mathrm{mL}{ }^{-1}$ after short exposure. ${ }^{125}$ On the contrary, one study showed that only high concentrations of graphene oxide (GO) (e.g., $\left.400 \mu \mathrm{g} \mathrm{mL}^{-1}\right)$ could cause a significant cellular toxic effect. ${ }^{\mathbf{1 2 6}}$ In addition, another study showed polyethylene-glycol-(PEG)ylated reduced graphene oxide (PrGO) neither induced toxicity nor impaired the differentiation potential of the stem cells. ${ }^{127}$ Moreover, another work showed that graphene quantum dots (GQDs) were internalized by hNSCs via the endocytosis mechanism, and had no significant change in the viability, proliferation, metabolic activity, and differentiation potential of hNSCs. ${ }^{128}$ Thus, various GQDs have been developed to be used as a bio-imaging probe for stem-celltherapy. ${ }^{128,129}$ Although such results are not completely comparable, it may suggest that the cytotoxicity of GO is size-, structure-, and morphology-dependent. Meanwhile, the reduced graphene oxide (rGO) NPs were also reported to present great compatibility but promote osteogenic differentiation of human MSCs. ${ }^{130}$ Yang et al. observed that graphene oxide (GO, hundreds of nanometers to several micrometers) could enhance the dopamine neuron differentiation of mouse embryonic stem cells (ESCs).$^{131}$ Moreover, GO with a diameter of $\sim 400 \mathrm{~nm}$ also presented strong ability to enhance self-renewal and accelerate differentiation of human fetal neural stem cells (hfNSCs). ${ }^{\mathbf{1 3 2}}$ Such effects may result from the efficient interactions between graphene-based NMs and bioactive molecules in culture medium or cytoplasmic membranes through electrostatic interaction, $\pi-\pi$ stacking, and hydrogen bonding. ${ }^{\mathbf{1 3 0 - 1 3 3}}$ Moreover, graphene/single-walled carbon nanotube (G/SWCNT) hybrids did not influence viability, but significantly affected the osteogenic and adipogenic differentiation of MSCs and subsequent associated expression levels of genes. ${ }^{\mathbf{1 3 4}}$ The possible mechanisms were the internalized G/SWCNT hybrids activated of the p38 signaling pathway and inhibited of the ERK1/2 signaling pathway, leading to upregulation of osteoblast-related genes and downregulation of adipocytic differentiation genes. ${ }^{\mathbf{1 3 4}}$

(3) Nanodiamonds. Compared with the CNTs and G-based NMs, nanodiamonds (NDs) are a relatively new type of carbon NMs that have the diamond-like structure with a size of nanometer scale. Considering its unique strong near-infrared (NIR) photoluminescence and magnetic properties, NDs have gained great interests in biomedical imaging and therapeutically applications. ${ }^{\mathbf{1 3 5 , 1 3 6}}$ Understanding the interaction between NDs and stem cells is the first step for the applications of NDs in stem-cell-therapy. Firstly, similar to other NPs, the cytotoxicity of NDs for stem cells was assessed. Xing et al. studied the genotoxicity of mouse embryonic stem cells (ESCs) induced by NDs. ${ }^{137}$ The results showed that the expression of DNA repair proteins slightly increased after being exposed the NDs to ESCs, such as p53 and MOGG-1. The oxidized nanodiamonds (O-NDs) were shown to cause more DNA damage than the pristine/raw NDs (R-NDs). ${ }^{137}$ However, compared with those induced by MWCNTs, the DNA damages caused by either the O-NDs or the R-NDs were much less severe. ${ }^{137}$ Afterwards, the possible effects of carboxylated NDs of $\sim 0.25 \mu \mathrm{m}$ in size labeling on the in vitro differentiation of hMSCs were discussed. ${ }^{\mathbf{1 3 8}}$ The differentiation potential and CD marker expressions for stem-like functionality were not altered upon ND label incorporation. Moreover, no secreted or intracellular protein changes indicative of stress or toxicity were detected. ${ }^{\mathbf{1 3 8}}$ This was further demonstrated in another study, which observed that NDs labeling did not alter the cellular morphology, proliferation, and the protein expression of stem cell marker SSEA-1 of embryonal carcinoma stem (ECS) cells. ${ }^{139}$

Overall, these results presumably suggest that the NDs are biocompatible and have no significant influence on differentiation ability of stem cells, and show enormous potential in labeling for stem cell localization and tracking in vivo.

3.3.3 Metal/metal-oxide NMs. Metal NPs such as gold ( $\mathrm{Au})$ or silver (Ag) are widely used as delivery carriers and diagnostic and/or therapeutic agents for biomedical applications. ${ }^{\mathbf{1 4 0 , 1 4 1}}$ The range of metal oxide NPs is broad, and each type of NPs has its unique properties for particular application. For example, iron oxide NPs such as $\mathrm{Fe}_{2} \mathrm{O}_{3}$ or $\mathrm{Fe}_{3} \mathrm{O}_{4}$ NPs are frequently used as magnetic resonance imaging (MRI) contrast agents in clinical applications due to their superparamagnetic nature; ${ }^{\mathbf{1 4 2}}$ titanium oxide $\left(\mathrm{TiO}_{2}\right)$ NPs are usually used in pharmaceutical applications owing to their whitening effect. ${ }^{\mathbf{1 4 3}}$ Over the past few decades, using the metal/metal-oxide NPs to modulate stem cells behaviors have acquired increasing attentions. In this section, we will provide a brief overview of the interactions between several metal/metal-oxide NPs with common usage and stem cells.

(1) Gold NPs. Because of their ease of synthesis, biocompatibility, and versatility for surface modification, gold-based NPs have been widely applied in drug delivery, diagnostic imaging, and photothermal therapy. With the advance development of nanotechnology, gold NPs have emerged as a modulator to mediate the stem cell fate. Over the past decades, the interactions between gold NPs (AuNPs) and stem cells, especially their effects on differentiation of stem cells have been extensively investigated. Yi et al. reported that $20 \mathrm{~nm}$ citrate protected AuNPs could be easily internalized by MSCs, and promote osteogenic differentiation and hinder adipogenic differentiation through the p38 mitogen-activated protein kinase (MAPK) pathway (Fig. 5A). ${ }^{\mathbf{1 4 4}}$ The success of osteogenicdifferentiation-inducing is also NP concentration-dependent, and only a relative high concentration of AuNPs ( $1 \mathrm{nM})$ promoted osteogenic differentiation. ${ }^{\mathbf{1 4 4}}$ In contrast, one work reported that the chitosan-conjugated AuNPs enhanced osteogenic differentiation but did not impact on adipogenic differentiation of human adipose-derived stem cells (hADSCs) through the Wnt/ $\beta$-catenin signaling pathway. ${ }^{145}$ Such difference might be attributed to the different surface chemistry. What is more, the physical and chemical properties of AuNPs including size, shape, and surface chemistry may influence multiple differentiation of stem cells. A range of AuNPs with different size $(15,30,50,75$ and $100 \mathrm{~nm})$ was synthesized. ${ }^{\mathbf{1 4 6}}$ Compared with the other sizes of gold NPs (15, 75 and $100 \mathrm{~nm})$, AuNPs with a diameter of 30 and $50 \mathrm{~nm}$ were more effective in enhancing osteogenic differentiation (Fig. 5B). ${ }^{146}$ Afterwards, a series of bovine serum albumin (BSA)-coated Au nanospheres 
(A)

(C)
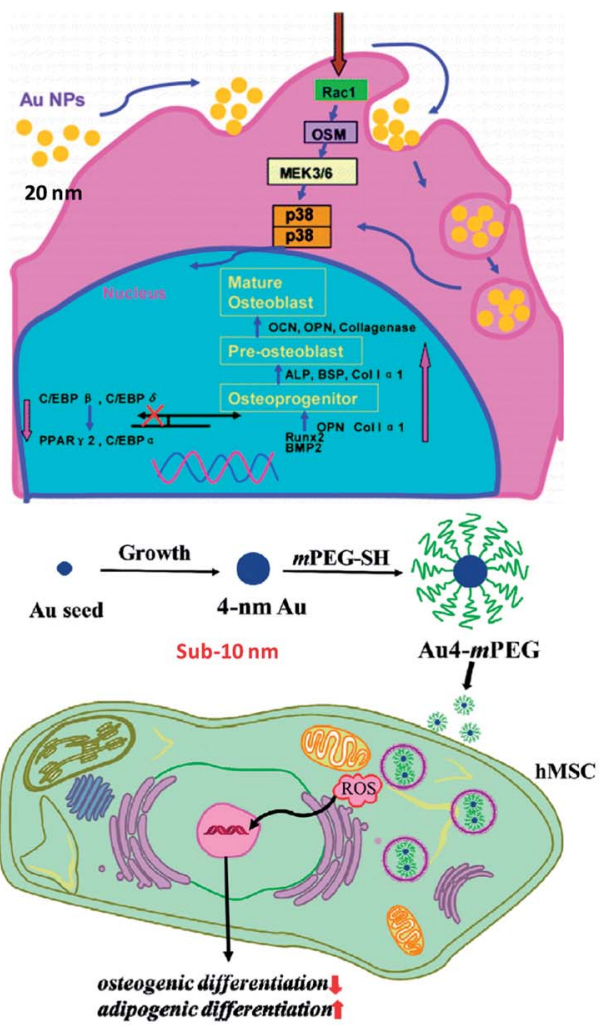

(B)

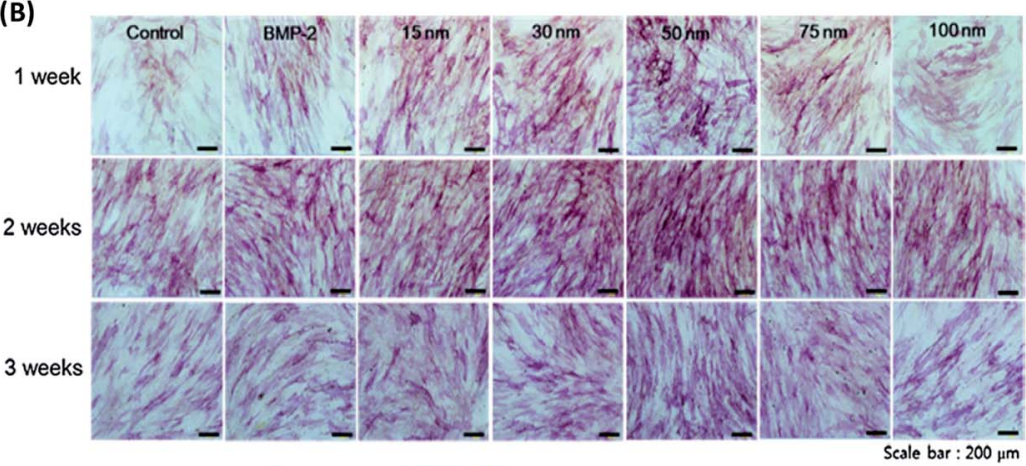

(D)
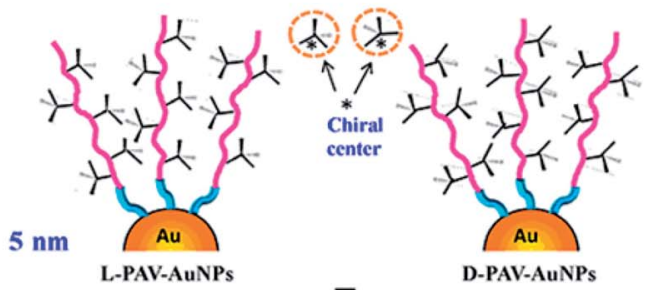

$\prod \begin{aligned} & \text { MSCs } \\ & \text { exposed }\end{aligned}$
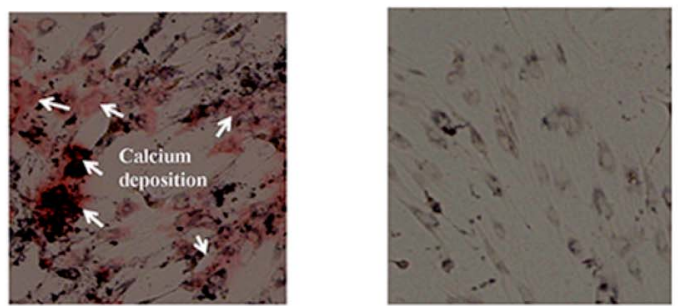

Chirality-dependent osteogenic differentiation of MSCs

Fig. 5 (A) Molecular mechanism of the modulation of osteogenic and adipocytic differentiation of MSCs by AuNPs through p38 MAPK signaling pathway. Reproduced with permission. ${ }^{144}$ Copyright 2010, American Chemical Society. (B) ALP staining and activity level during the process of differentiation from ADSCs toward osteoblasts for 3 weeks: ALP stained cells, which were treated with osteogenic medium alone (control), BMP2, and each size of GNPs for 3 weeks as observed by an optical microscope. Reproduced with permission. ${ }^{146}$ Copyright 2014, Elsevier. (C) Schematic illustrations of the fabrication process of Au4-mPEG NPs, and the possible molecular mechanism of the inhibitive effect of Au4-mPEG NPs on osteogenic differentiation and their promotive effect on adipogenic differentiation. Reproduced with permission. ${ }^{148}$ Copyright 2017 , Royal Society Chemistry. (D) Schematic diagrams of the effects of the surface chirality at the nanoscale on osteogenic differentiation of MSCs. Reproduced with permission. ${ }^{150}$ Copyright 2016, Springer.

(sphere-40, sphere-70, sphere-110), Au nanostars (star-40, star70, star-110) and Au nanorods (rod-40, rod-70, rod-110) with diameters of 40,70 and $110 \mathrm{~nm}$ were synthesized, respectively. ${ }^{\mathbf{1 4 7}}$ Subsequently, their effects on osteogenic differentiation of MSCs were examined. ${ }^{\mathbf{1 4 7}}$ Obviously, osteogenic differentiation of MSCs induced by AuNPs was size-relied and morphology-dependent. Sphere-40, sphere-70 and rod-70 significantly promoted osteogenic differentiation while rod-40 inhibited it. Star-40, star-70, star-110, sphere-110 and rod-110 showed negligible influence on osteogenic differentiation. ${ }^{\mathbf{1 4 7}}$ This was further confirmed by the study, in which AuNPs with a diameter of $40 \mathrm{~nm}$ promoted osteogenic differentiation through the enhancement of cytoskeleton tension and cellular Young's modulus. ${ }^{148}$ However, sub-10 nm AuNPs (e.g., $4 \mathrm{~nm}$ ) showed an active effect on adipogenic differentiation and inhibitive effect on osteogenic differentiation of MSCs due to the highly induced ROS level (Fig. 5C). ${ }^{\mathbf{1 4 8}}$ In addition, AuNPs with amine (AuNP-NH2, $21.76 \pm 3.93 \mathrm{~nm}$ ), carboxyl (AuNP$\mathrm{COOH}, 17.08 \pm 2.28 \mathrm{~nm}$ ) and hydroxyl (AuNP-OH, $12.42 \pm 1.33$ $\mathrm{nm}$ ) functionalized were fabricated. ${ }^{149}$ AuNP-NH2 and AuNP$\mathrm{OH}$ did not inhibit osteogenic differentiation, while AuNP$\mathrm{COOH}$ significantly reduced ALP activity and matrix mineralization in MSCs through an upregulation of TGF- $\beta$ and FGF-2 expression, which enhanced cell proliferation over osteogenic differentiation. ${ }^{149}$ Interestingly, the surface molecular conformation was also observed to have the ability to modulate the differentiation of stem cells. More recently, our group has evaluated the effect of molecular chiral poly(acryloyl-L(D)-valine) (L(D)-PAV)-anchored gold NPs (L(D)-PAV-AuNPs) on the differentiation of rat mesenchymal stem cells (rMSCs). ${ }^{150}$ L-PAVAuNPs promoted osteogenic differentiation through activating the p38 mitogen-activated protein kinase (MAPK) pathway and exerting mechanical stress on MSCs, while D-PAV-AuNPs had no 
obvious effects on osteogenic differentiation of MSCs (Fig. 5D). ${ }^{150}$

(2) Silver nanoparticles. Silver nanoparticles (AgNPs) have drawn appealing lights in regenerative medicine due to their excellent antimicrobial properties. AgNPs as a valuable NMs are usually encapsulated in the scaffolds to repair skin, bone defects, with a reduced incidence of infection. ${ }^{151,152}$ Thus, the effect of AgNPs on the viability and differentiation potential of stem cells are urgently needed to be assessed. Firstly, the toxicities of AgNPs, especially the effects of its surface chemical compositions (polysaccharide- and hydrocarbon-coated) on the self-renewal and cell cycle of mESCs were evaluated. ${ }^{153}$ Both polysaccharide- and hydrocarbon-coated AgNPs altered the cell morphology of mouse embryonic stem cells (mESCs). Cell cycle of mESCs induced by the two types of AgNPs arrested at G1 and $S$ phases through inhibition of the hyperphosphorylation of Retinoblastoma $(\mathrm{Rb})$ protein. ${ }^{153}$ Such effects were resulted from the overproduction of reactive oxygen species (ROS), the reduced AgNPs toxicity for the polysaccharide coating was due to the reduced ROS production. ${ }^{153}$ The cytotoxicity of AgNPs was also certified by R. J. Cooper et al., who observed that low level of AgNP exposure could disrupt the cytoskeleton structure in cultured adult neural stem cells (NSCs), resulting in inhibition of neurite dynamics and the formation of F-actin puncta. ${ }^{154}$ Concentration-dependent toxicity was observed at an AgNP concentration of above $4 \mu \mathrm{g} \mathrm{mL} \mathrm{m}^{-1}$ for urine-derived stem cells. ${ }^{155}$ Furthermore, AgNPs could enhance osteogenic differentiation, and be accompanied with inducing actin polymerization, increasing cytoskeleton tension, and activating RhoA at the NP concentration of $4 \mu \mathrm{g} \mathrm{mL} .{ }^{155}$ Interestingly, the $\mathrm{AgNO}_{3}$ did not have such effects, which indicated that the promotion of osteogenic differentiation was induced by AgNPs themselves, rather than the silver ions. ${ }^{155}$ However, Pauksch et al. reported the internalized AgNPs did not induce alterations in osteoclastogenesis. ${ }^{156}$ With regard to their cytotoxicity and the potential effects on stem cell differentiation, further studies are needed to keep a balance between the antibacterial benefit and the potential health risks of AgNPs.

(3) Iron oxide nanoparticles. Iron oxide nanoparticles (IONPs) have been widely used as magnetic resonance imaging (MRI) and magnetic targeting agents in biomedical applications due to their great ability to respond to magnetic fields. IONPs were proposed as an MRI tracking of stem cells in regenerative medicine and other stem-cell-therapies. Similar to other NPs, the potential adverse effects of IONPs can limit the practically and applicability of their usage. Thus, studying the biological impact of IONPs on stem cell is crucial, especially for their effects on differentiation potential of stem cells. Firstly, the IONP-induced osteogenic differentiation of MSCs and the associated molecular mechanisms were explored. ${ }^{157}$ IONPs with a diameter of $\sim 8.2 \mathrm{~nm}$ were fabricated (Fig. 6A and B). The characteristic results indicated that both types of IONPs were superparamagnetic and with own high saturation magnetization (Fig. 6C). Moreover, IONPs were structurally stable in MSCs and enhanced ALP activity and mineralization deposition of MSCs, rather than the soluble $\mathrm{Fe}^{3+}$ (Fig. 6D and E). At the molecular level, IONP unregulated long noncoding RNA
INZEB2, which is indispensable for maintaining osteogenesis of MSCs (Fig. $6 \mathrm{~F}-\mathrm{H}$ ) ${ }^{157}$ In order to further understand the molecular mechanisms, gene microarray assay and bioinformatics analysis were performed..$^{158}$ These results observed that gene expression was widely regulated and the classical mitogenactivated protein kinase (MAPK) signal pathway was activated by IONPs treatment. ${ }^{158}$ As a result, osteogenic differentiation was promoted due to the downstream genes of the MAPK signal pathway. ${ }^{158}$ Meanwhile, the effects of surface functionalization of IONPs on differentiation of MSCs were studied. Shrestha et al. fabricated two kinds of IONPs with similar sizes $(\sim 10 \mathrm{~nm})$ but different surface chemistry, i.e. one in its pristine form (without extra molecules capped, P-NPs) and the other coated with citrate (C-NPs) ${ }^{159}$ No significant difference in cellular uptake kinetics or cytotoxicity was observed for the two types of IONPs. Osteogenic differentiation of MSCs was markedly impaired by incubation with C-NPs, as evidenced by significantly reduced expression of collagen type I and osteocalcin and calcium deposition. However, P-NPs did not impact on osteogenic and adipogenic differentiation. ${ }^{159}$ Since one of the unique features of IONPs is their response to magnetic field, enabling their applications in drug targeting and cellular uptake enhancing, the magnetic field may have an effect on differentiation of stem cells. Recently, Jiang et al. fabricated IONPsloaded bovine serum albumin (BSA) $\left(\mathrm{Fe}_{3} \mathrm{O}_{4} / \mathrm{BSA}\right) \mathrm{NPs}$, which showed tunable magnetic property. ${ }^{160}$ The external magnetic field strongly enhanced cellular uptake of $\mathrm{Fe}_{3} \mathrm{O}_{4} / \mathrm{BSA}$ NPs. Furthermore, the static magnetic field also markedly promoted osteogenic differentiation of MSCs after internalized $\mathrm{Fe}_{3} \mathrm{O}_{4} / \mathrm{BSA}$ NPs, as evidenced by increased ALP activity, calcium deposition, and expressions of COL I and osteocalcin at both mRNA and protein levels. ${ }^{160}$ In sum, the IONPs may have great potential to be used as a differentiation-inducing agent for stem-celltherapy application. With the pondering of their possibly impacts on differentiation of stem cells, the application of IONPs in bio-imaging should be concerned.

(4) Zinc oxide NPs. Zinc oxide (ZnO) NPs are another metal oxide NMs and have a wide variety of applications, while their hidden effects on stem cell behaviors remain to be poorly understood. Recently, the interactions with ZnO NPs and stem cells were evaluated. Similar to other NPs, the cytotoxic effects of ZnO NPs on stem cells were firstly concerned. The cellular toxicity of ZnO NPs was positively correlated with the dose of ZnO NPs. ${ }^{161}$ It's worth noting that even low concentrations of ZnO NPs $\left(10 \mu \mathrm{g} \mathrm{mL}^{-1}\right)$ could induce significant cytotoxicity. ${ }^{162}$ The high level of reactive oxygen species (ROS) generation and the dissolved $\mathrm{Zn}^{2+}$ in the culture medium or inside cells were observed to be the main cause of the cytotoxicity of $\mathrm{ZnO}$ NPs. ${ }^{161,163}$ Thus, ZnO NPs should be used with caution if there is a dermatological problem. Besides cellular toxicity, it was observed that the effects of ZnO NPs on osteogenic differentiation were dose-dependent. ${ }^{164}$ MSCs treated with $30 \mu \mathrm{g} \mathrm{mL}{ }^{-1}$ ZnO NPs enhanced osteogenic differentiation, while the $60 \mu \mathrm{g}$ $\mathrm{mL}^{-1}$ ZnO NPs treatment had no obvious such effects. ${ }^{164}$

(5) Other metal or metal oxide NPs. Advanced development in nanotechnology allows scientists to fabricate various types of metal or metal oxide NPs for stem-cell-therapy application. 

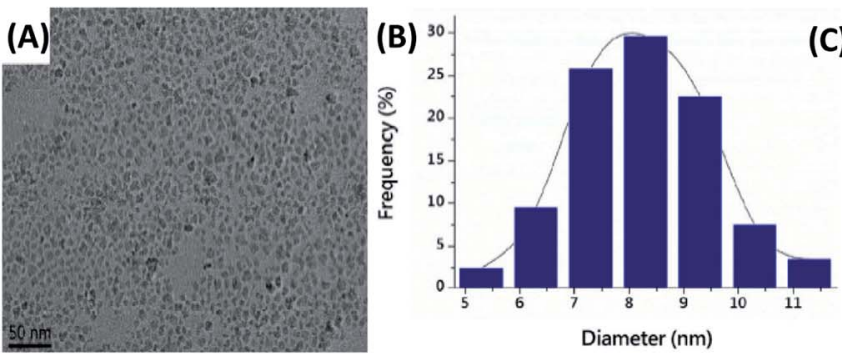

(E)
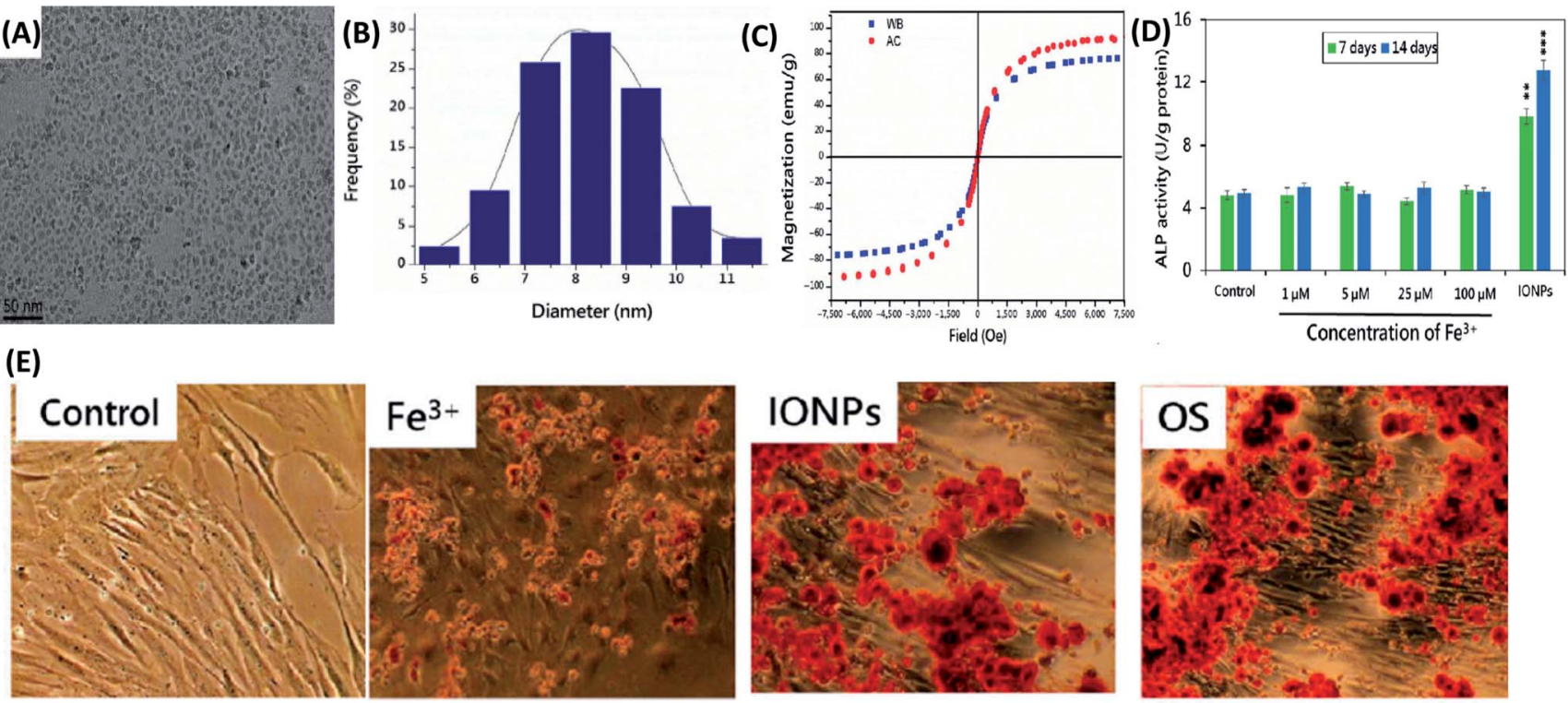

(F)

(G)
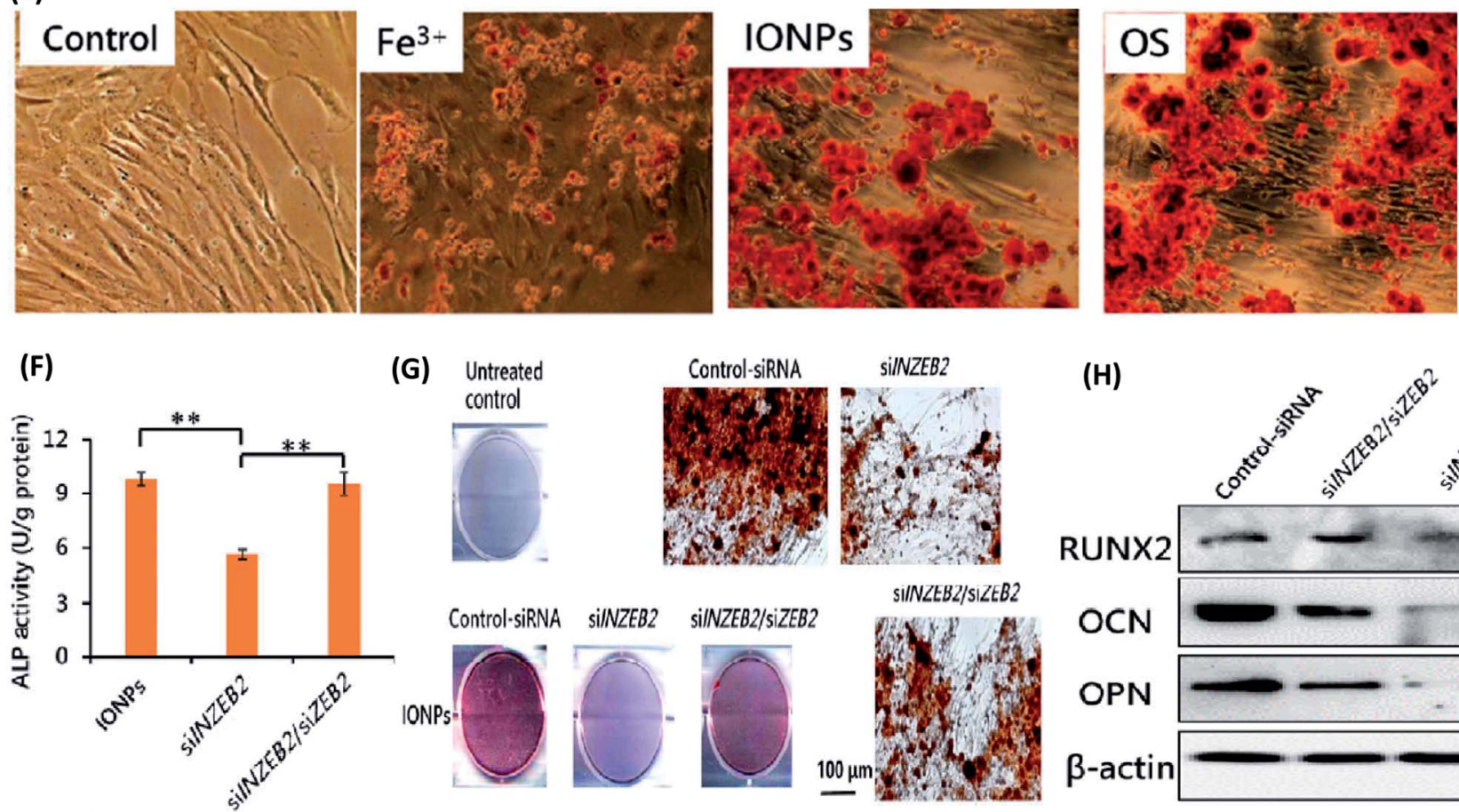

(H)
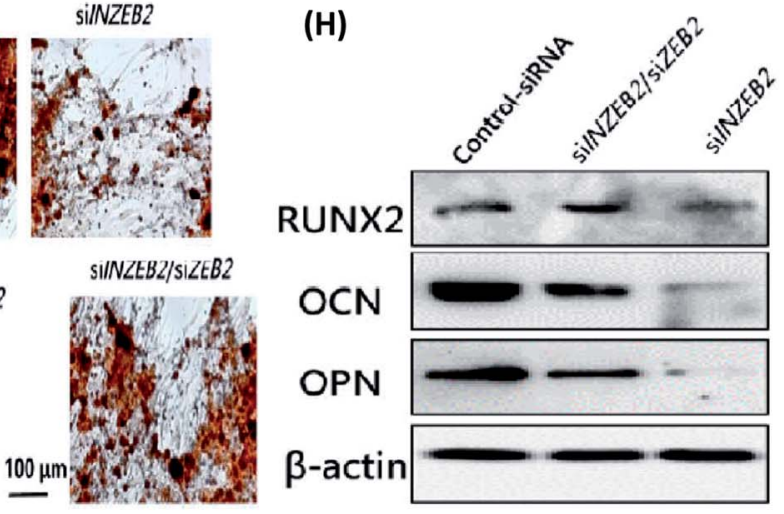

Fig. 6 Iron NPs accelerate osteogenic differentiation of MSCs via modulation of long noncoding RNA INZEB2. (A) TEM image of IONPs. (B) Size distribution histogram of IONPs. (C) The hysteresis loop of IONPs. WB and AC represent IONPs that were synthesized in heat mode in a water bath and in an alternating-current (AC) magnetic field. (D) Effects of different concentrations of Fe ${ }^{3+}$ on the ALP activity of MSCs. (E) Alizarin Red S staining images. MSC were treated with $100 \mu \mathrm{M} \mathrm{Fe}^{3+}, 100 \mu \mathrm{g} \mathrm{mL}^{-1}$ IONPs, or osteogenesis-inducing supplements (OS) for 21 days. (F) Effects on ALP activity of MSCs after transfection with the indicated siRNA. (G) Alizarin Red S staining images. Effects on the mineralized-nodule formation in MSCs after transfection with the indicated siRNA. $(\mathrm{H})$ Effects on the protein levels measured by western blotting after transfection with the indicated siRNA. All bars represent mean $\pm \mathrm{SD}, n=3,{ }^{* *} p<0.01 ; * * * p<0.001$. Reproduced with permission. ${ }^{157}$ Copyright 2017, Springer.

Apart from the NPs mentioned above, others including titanium dioxide $\left(\mathrm{TiO}_{2}\right)$, copper oxide $(\mathrm{CuO})$, cerium oxide $\left(\mathrm{CeO}_{2}\right)$ and upconversion NPs also have great potential in stem-cell-therapy application. For example, $\mathrm{TiO}_{2}$ nanotubes were acted as drug nanoreservoirs for modulating the mobility and differentiation of MSCs. ${ }^{165}$ Moreover, the $\mathrm{TiO}_{2}$ NP itself can also be used as a modulator for mediating stem cell behaviors. Liu et al. observed that $\mathrm{TiO}_{2}$ NPs enhanced a differentiation tendency towards neurons from neural stem cells. ${ }^{166}$ Nonetheless, other studies observed that $\mathrm{TiO}_{2}$ NPs had negative effects on cell viability and differentiation of MSCs in a dose- and sizedependent manner. ${ }^{167}$ Simultaneously, the influence of surface functionalization of $\mathrm{TiO}_{2} \mathrm{NPs}$ on differentiation of stem cells was examined. $\mathrm{TiO}_{2} \mathrm{NRs}$ with different surface functional groups, i.e. amines $\left(-\mathrm{NH}_{2}\right)$, carboxyl groups $(-\mathrm{COOH})$ and poly(ethylene glycol) (-PEG) were fabricated and their flowing impacts on the differentiation of rat bone MSCs (rBMSCs) were studied. ${ }^{168}$ Compared with $\mathrm{TiO}_{2}-\mathrm{COOH}$ and $\mathrm{TiO}_{2}-\mathrm{PEG}$ NRs, $\mathrm{TiO}_{2}-\mathrm{NH}_{2}$ NRs significantly enhanced cellular uptake efficiency. ${ }^{168}$ All the $\mathrm{TiO}_{2}-\mathrm{NRs}\left(\mathrm{TiO}_{2}-\mathrm{NH}_{2} \mathrm{NRs}, \mathrm{TiO}_{2}-\mathrm{COOH} \mathrm{NRs}\right.$ and $\mathrm{TiO}_{2}-\mathrm{PEG} \mathrm{NRs}$ ) presented no cytotoxicity and genotoxicity on MSCs at tested concentrations. Moreover, $\mathrm{TiO}_{2} \mathrm{NRs}$ did not show an obvious influence on the adipogenic differentiation potential of the MSCs. ${ }^{168}$ However, $\mathrm{TiO}_{2}-\mathrm{COOH}$ NRs showed a significant impairment on the osteogenic differentiation due to the up-regulation of transforming growth factor beta 1 (TGFB1) and fibroblast growth factor (FGF-2). ${ }^{168}$

In addition, the cytotoxicity and genotoxicity of CuO NPs with a similar size but different surface chemistry (CuO-core, $\mathrm{CuO}-\mathrm{COOH}, \mathrm{CuO}-\mathrm{NH}_{2}$ and CuO-PEG NPs) on rBMSCs were also investigated. ${ }^{169} \mathrm{CuO}$ NPs showed dose-regarded and surface-chemistry-dependent toxicity to MSCs. The cytotoxicity 
of all the types of $\mathrm{CuO}$ NPs exhibited no obvious difference at the lower concentration $\left(<20 \mu \mathrm{g} \mathrm{mL}^{-1}, 72 \mathrm{~h}\right)$, while the CuO-core and $\mathrm{CuO}-\mathrm{COOH}$ were observed significantly larger cytotoxicity than the $\mathrm{CuO}-\mathrm{NH}_{2}$ and $\mathrm{CuO}-\mathrm{PEG}$ at the higher concentration $\left(>20 \mu \mathrm{g} \mathrm{mL}{ }^{-1}, 72 \mathrm{~h}\right) .{ }^{169}$ Despite their large cytotoxicity at high concentrations, all the CuO NPs showed only a slight DNA damage. ${ }^{169}$ Interestingly, all the $\mathrm{CuO}$ NPs had no significant effect on the differentiation potential of the MSCs. ${ }^{169}$ Recently, the effects of cerium oxide $\left(\mathrm{CeO}_{2}\right)$ NPs on the proliferation, differentiation and mineralization function of primary osteoblasts were studied. ${ }^{\mathbf{1 7 0}}$ The cytotoxicity of $\mathrm{CeO}_{2}$ NPs on primary osteoblasts was size- and incubation time-dependent. $\mathrm{CeO}_{2} \mathrm{NPs}$ with a diameter of $40 \mathrm{~nm}$ facilitated the differentiation of osteoblasts, and the promotion rates were enhanced with increasing NP concentration. ${ }^{170}$ However, the $60 \mathrm{~nm} \mathrm{CeO}{ }_{2} \mathrm{NPS}$ promoted the differentiation of osteoblasts at lower concentrations, and inhibited the differentiation at higher concentrations. Moreover, the two $\mathrm{CeO}_{2}$ NPs accelerated the adipogenic transdifferentiation of osteoblasts, and this effect of $40 \mathrm{~nm}$ $\mathrm{CeO}_{2}$ NPs was weaker than that of $60 \mathrm{~nm} \mathrm{CeO}_{2}$ NPs. ${ }^{\mathbf{1 7 0}}$ Another study reported that $\mathrm{CeO}_{2}$ NPs could efficiently inhibit the maturation of MSCs toward adipocytes due to their strong ability to decrease the ROS degree necessities during adipogenesis. ${ }^{171}$

\section{The interactions between NPs and stem cells and possible underlying mechanisms}

Our previous sections provide a full overview of the various types of NPs that have been described to be associated with stem cell modulation (Table 1). So far, the wide variety in NP parameters and experimental setups impedes a clear understanding of how NPs can result in stem cell differentiation induction. In order to fully understand the impacts of the different NP-associated parameters on stem cell behaviors, it is essential to conduct a deep examination that is concentrated on the differentiation-modulating potential of a narrow set of NPs with difference from each other in only a single physicochemical property. This is assuredly a challenging task due to the fact that changing one parameter (e.g., surface charge) is often accompanied by affecting other factors (e.g., hydrodynamic size, colloidal stability), by which the ability to link NP physiological properties with the observed cellular effects is limited. Thus, it needs a systematic experimental setup, which underscores the importance of further study on controllable synthesis of NPs as well as the relevance of extensive NP characterization. Besides that, the cell culture conditions including $\mathrm{pH}$, cellular type and etc., need to be fixed.

The interaction of NPs with the stem cell membrane plays an essential role in diagnostics, drug delivery and therapy applications. NPs can easily transfer across cells membranes and distribute in the cytoplasm or lysosome, thus activating or inhibit certain cellular signaling pathways for differentiation induction or inhibition. ${ }^{\mathbf{1 7 2 , 1 7 3}}$ NPs are internalized via different endocytosis pathways ${ }^{\mathbf{1 5 0 , 1 7 4}}$ including clathrin-mediated endocytosis, caveolin-mediated endocytosis, macropinocytosis and clathrin- and caveolin-independent endocytosis, cellular internalization of NPs and the possible mechanism of differentiation induced by NPs are significantly influenced by the physicochemical properties of NPs, such as size, shape, hydrophobicity, softness, composition and surface chemistry of nanoparticle surfaces. ${ }^{4}$

The optimal size of NPs for stem cell differentiation almost ranges from $20 \mathrm{~nm}$ to $70 \mathrm{~nm}$ possibly due to the size-dependent cellular uptake rates. ${ }^{147,175}$ The NPs around $30-50 \mathrm{~nm}$ in size presented higher amounts cellular uptake by cells. While the NP size in the range of 50-200 $\mathrm{nm}$ has been shown to have minor influences on cellular uptake. ${ }^{147,175}$ Besides that, the shape of NPs also affects the cellular uptake that may influence the stem cell differentiation. ${ }^{\mathbf{1 4 7}}$ The internalization rate of nanospheres (NSs) is much higher than that of nanorods or quasi-ellipsoid counterparts with the similar size. ${ }^{176,177}$ The uptake rate of NPs by MSCs decreased with an increase in the aspect ratio (polar axis: equatorial axis). These effects were probably due to the fact that cells needed to wrap around the polar axis (pole) of NPs during the internalization process. The stretched NPs have been shown to preferentially absorb on the cell membrane along their polar axis, making it more difficult for the highly stretched NPs to be internalized. ${ }^{177}$ In another study, the cellular uptake of polystyrene NSs (diameter: $20 \mathrm{~nm}$ ) and nanodiscs (diameter: $20 \mathrm{~nm}$; thickness: $2 \mathrm{~nm}$ ) was evaluated. ${ }^{178}$ NSs were easily internalized into cells, whereas nanodiscs were primarily adsorbed on the cell membranes. ${ }^{178}$ The further studies showed that the capability of NSs to penetrate the lipid bilayers was nearly six times higher than that of nanodiscs, while membrane retention of nanodiscs was eight times higher than that of NSs. ${ }^{178}$ Additionally, surface charges and chemical moieties affect the uptake of NPs, and positively charged ones showed higher cellular uptake and larger cytotoxicity. Surface chemical moieties like amines $\left(-\mathrm{NH}_{2}\right)$, carboxyl $(-\mathrm{COOH})$ and hydroxyl $(-\mathrm{OH})$ are widely existed in biomolecules such as proteins, nucleic acids, lipids and polysaccharides, affecting the behavior and differentiation of stem cells. ${ }^{179}$ For instance, COOH-AuNPs treatment inhibits osteogenic differentiation obviously, whereas those $-\mathrm{NH}_{2}$ and $-\mathrm{OH}$ groups functionalized ones fail to do so. ${ }^{179}$ Moreover, it was observed that AuNPs enhance osteogenic differentiation of MSCs through the p38 MAPK pathway, while chitosan conjugated ones activate the Wnt/ $\beta$-catenin signaling pathway in hADSCs. ${ }^{144,180}$ Apart from the above NP parameters, the hydrophobic and mechanical properties also could influence the stem cell behavior. ${ }^{\mathbf{1 8 1}}$ The softer and more hydrophobic NPs were internalized to a greater extent. Hydrophobicity could modulate the interactions of NPs with components of the cellular microenvironment, such as serum proteins, lipid membranes and intracellular uptake. Hydrophobic NPs fabricated from poly(n-butylmethacrylate) (PBMA), poly(hexyl methacrylate) (PHMA), and poly(lauryl methacrylate) (PLMA) are taken up more easily compared with the hydrophilic ones synthesized from poly(methyl methacrylate) (PMMA), poly(propyl methacrylate) (PPMA), and poly(stearyl methacrylate) (PSMA). ${ }^{181}$ However, the underlying mechanism of the enhanced cellular uptake by softer nanoparticles is still unclear. 
苛苛䒠

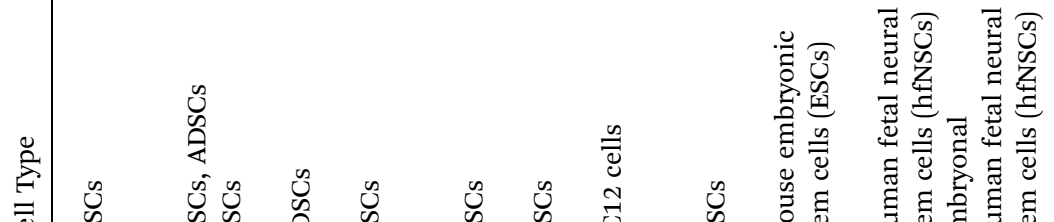

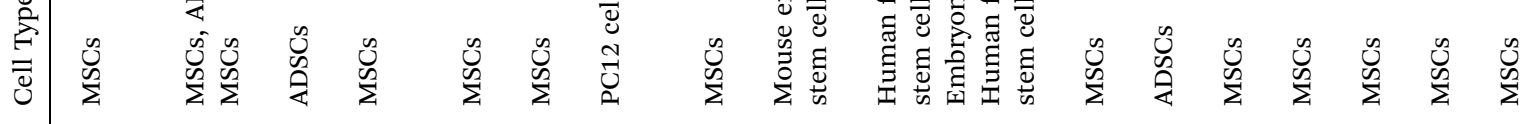

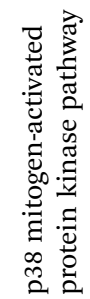
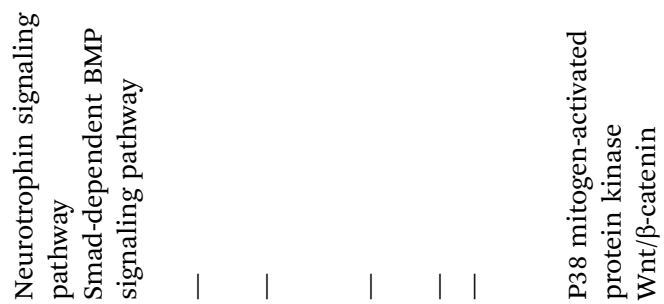

节

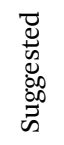
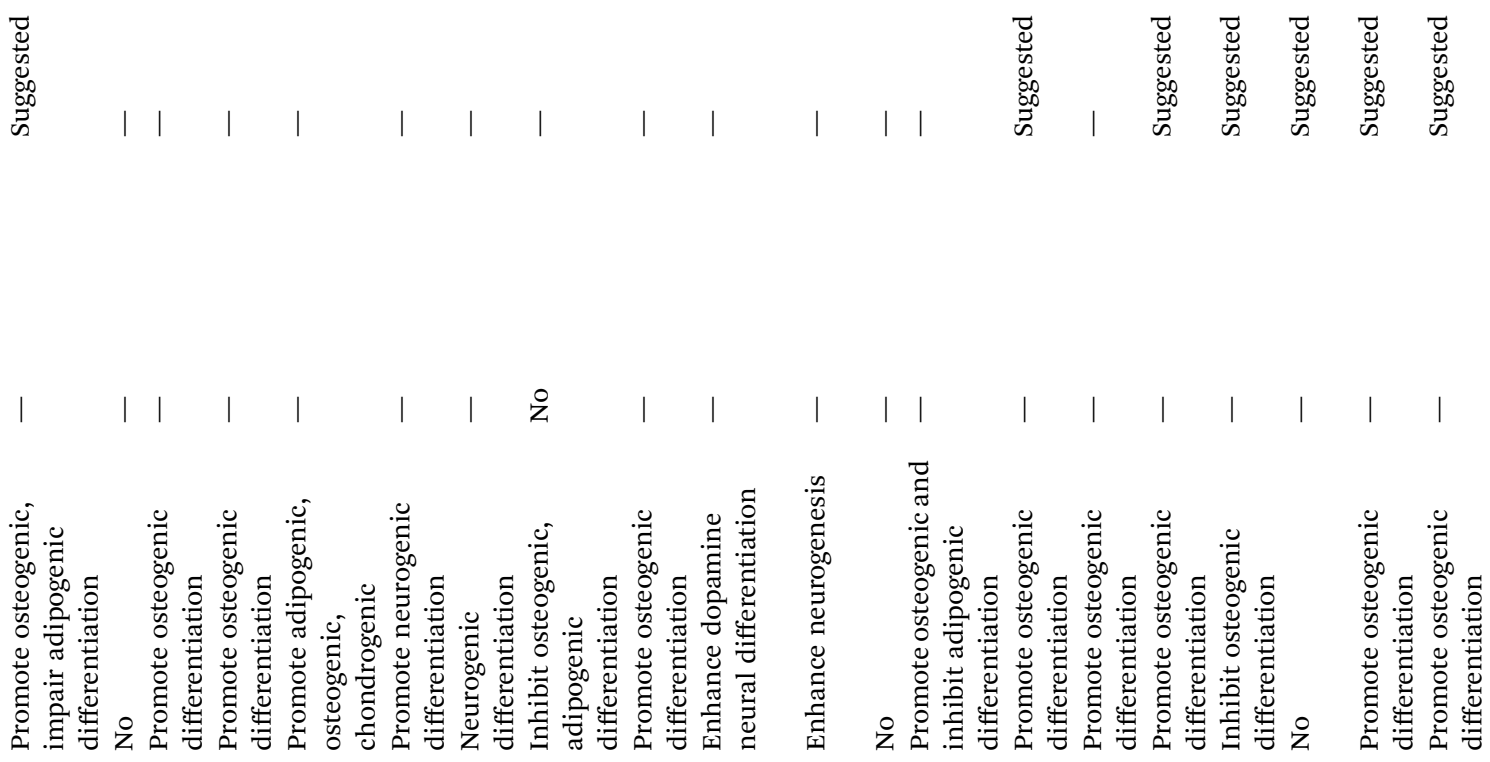

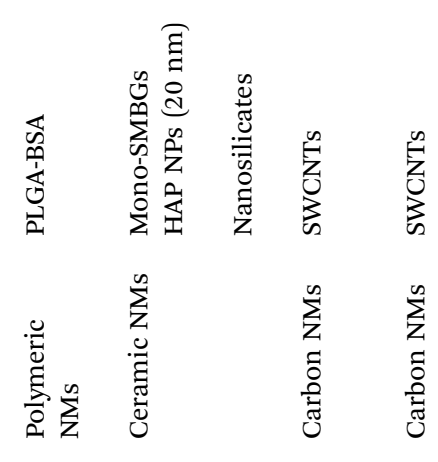

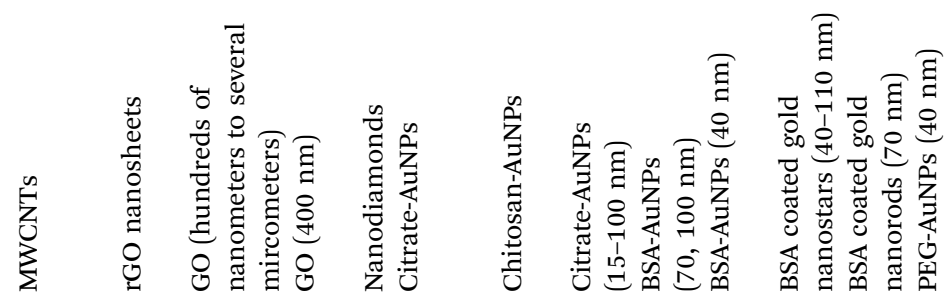




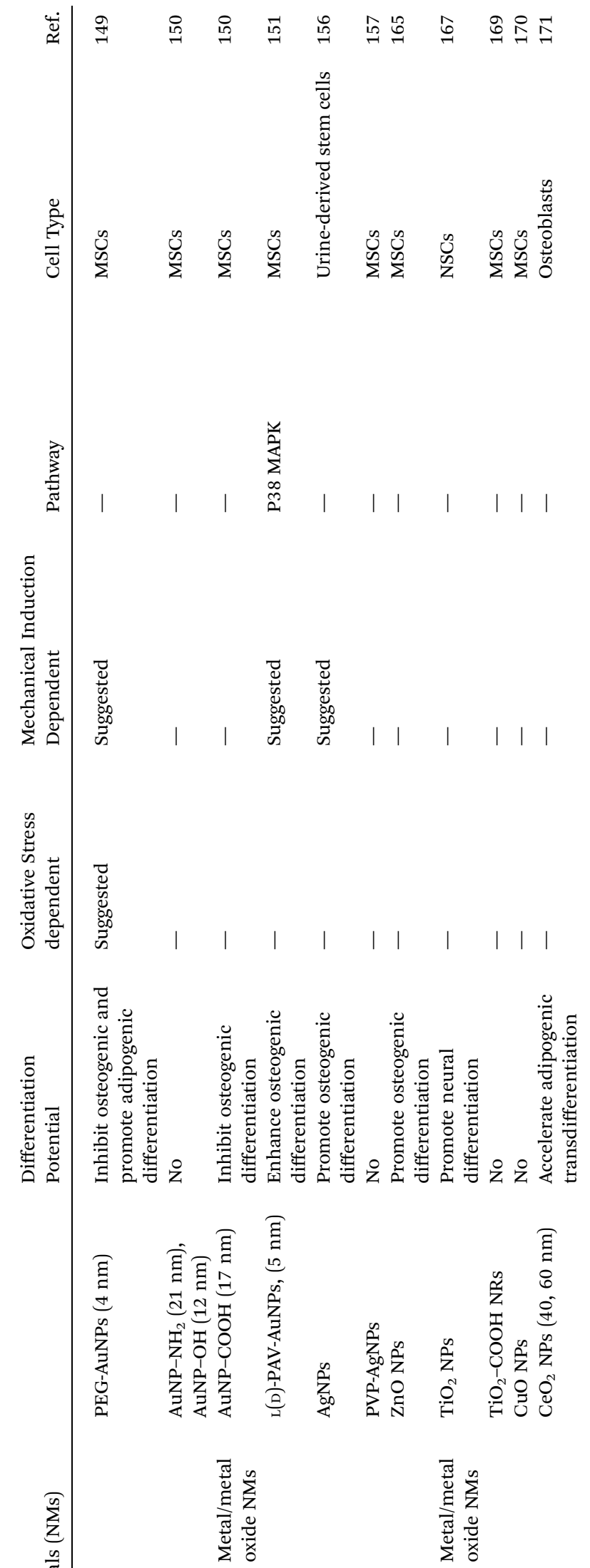

퓰 $\sum_{Z}^{n}$
It is hypothesized that soft NPs could deform easily upon cellular contact, resulting in a more favorable interaction with cell membranes compared to the harder counterparts. ${ }^{4}$ Notably, the interactions of NPs and stem cells have not clearly explained, as most physicochemical parameters are entangled.

Recent years, more and more literature discusses NPinduced effects on differentiation potential of stem cells. ${ }^{4}$ Indeed, NPs have been recognized as a new class of differentiation activators affecting it through various pathways such as oxidative stress. ${ }^{\mathbf{1 8 2}}$ ROS production has been reported to be one of the main causes of cytotoxicity for almost all NPs and is considered as a potential common byproduct of NP exposure. An increasing amount of evidence has suggested that cell differentiation is significantly influenced by ROS. Su et al. found that ROS promoted vascular smooth muscle cell differentiation via the p38/MAPK-dependent pathway. ${ }^{\mathbf{1 8 3}}$ In contrast, Mody et al. showed that ROS inhibited the differentiation of bone preosteoblast cell line MC3T3-E1. ${ }^{\mathbf{1 8 4}}$ These results suggest that the changes in intracellular ROS generation are a general regulation mechanism for differentiation of stem cell, but lineage-specific differentiation regulation still need to be further discussed. However, the increasing evidence seems to show that high levels of ROS will propel adipogenesis but impede osteogenesis of stem cell. ${ }^{148}$ NPs can provoke ROS generation through multiple interactions. Firstly, NPmitochondria interaction can cause mitochondrial membrane damage, leading to disruption of the respiratory chain, and resulting in increased ROS production. Secondly, the direct interactions between NPs and intracellular enzymes that could maintain cellular redox potential. Furthermore, NP-integrin interaction also could activate intracellular signaling pathway that in turn trigger ROS generation. Besides, the degradation byproducts of NPs such as metal ions that can induce ROS production.

Mechanical stress also plays a vital role in differentiation potential change of stem cells. The accumulation of NPs inside the cells may cause cell cytoskeleton and cellular mechanical property change. ${ }^{\mathbf{1 8 5}}$ More and more evidence implicate that high mechanical property promoted osteogenic differentiation but inhibited adipogenic differentiation of stem cells. ${ }^{186}$ The intracellular NP may affect cytoskeleton assembly and increase the Young's modulus of stem cells, enhance the following osteogenic differentiation. ${ }^{\mathbf{1 4 8}}$

Upon NPs contact with cells, they will interact with cell membranes and be internalized by stem cells, are encapsulated into vesicles and then transported inside the cells. This process was a dynamic process and NPs were movable continually. During these process, NPs will interact with membrane receptors of the cells or intracellular biomolecules may trigger cellular signaling pathway to induce the specific differentiation of stem cells. ${ }^{24}$ Since the complexes of the cellular environment and various of NPs, it is hard to distinguish the interaction between the cellular biomolecules with NPs. In addition, the surface protein adsorption and the potential cytotoxicity (e.g., lysosomal dysfunction) induced by NPs may play a substantial role in impacting the fate of stem cells. 
Actually, cell differentiation mediated by NPs is a very complicated process that relates to many possible mechanisms and signaling pathways. Maybe future efforts should be made to fully understand the mechanisms of stem cell differentiation influenced by NPs.

\section{Conclusions and perspectives}

In the current review, we have summarized the application of NMs for stem cell therapy and the interaction between NMs and stem cells. NMs as carriers or imaging agents have been widely applied in stem cell therapy, which has led to the attention of NMs themselves intervening stem cell behavior such as toxicity, differentiation and so on. Accumulating evidence certificates that the emerging possibility that nanotechnology offers for monitoring and manipulation of stem cells at a nanoscale level. Although a few NMs alone or as a conjugated inductive agent have been successfully applied in stem cell therapy, it remains a challenge to completely realize this promise.

One challenge is to gain a deeper understanding of the longterm effects of each component of the NPs on stem cell fate in vitro and in vivo. The influence of NP physical and chemical properties including composition, surface functionality, structure, morphology and size on stem cell differentiation should be systematically evaluated. The increasing evidence showed that NPs could activate or inhibit differentiation in a variety of stem cell types. More interestingly, some NPs have presented their intrinsic selectivity in inducing or inhibiting differentiation in stem cells. However, investigations of how NMs interact with stem cells and their subsequent intracellular stability is still limited. Moreover, considerable ranges of particles including biodegradable polymeric particles and some metal or metal oxide particles are not stable, and release ions or molecules under the acidic and enzymatic intracellular environment. These released ions or molecules have a large potential to affect the viability and fate of stem cells. Considering this, two kinds of biodegradable NMs, chitosan and DNA nanostructures, are worth exploring as nanocarriers for drug delivery due to their low toxicity. Moreover, $\mathrm{TiO}_{2}, \mathrm{GO}$, NDs and CNTs are ideal biocompatible and mechanically platforms that are worth searching for $2 \mathrm{D}$ matrix supports or $3 \mathrm{D}$ nano-scaffolds to facilitate stem cell differentiation. Apart from cell types, microenvironment should also be considered, which may influence the interactions of the NMs and stem cells. Additionally, compared with the traditional induction medium, the NP especially the soft NM inducing effects on stem cell differentiation are relatively weak. Therefore, the NP should be designed with certain structure and bioactive characteristics in the future, which present low cytotoxicity and strong capability to control stem cell differentiation to specific lineages upon desired.

Simultaneously, a continuous challenge exists to investigate the possible mechanism of stem cell fates influenced by NMs. Future studies are necessary to research the stem cell-NP interaction and the associated signal pathway relevant to the cell differentiation. In addition, the mechanical stress of the stem cells caused by the NPs especially the hard NMs should be cared. Maybe the best solution is to properly visualize the interactions of stem cells within the microenvironment. The advanced development of nanotechnology may facilitate the realization of the real time imaging during the monitoring stem cell behaviors in a more realistic environment as opposed to in a culture dish. Thus, the observation of NM interactions in stem cell-therapy applications will remain a fundamental design process. The new inductive mechanisms will start to attract the research community interests.

Finally, developing novel biocompatible and multifunctional NMs as nanocarriers or imaging agents for stem cell therapy is urgently needed. The advances in nano-synthetic chemistry and nanotechnology allowed the generation of numerous NMs with desirable morphology, nanostructure, physiochemical properties and biological effects. Therefore, it is highly expected that more NMs will be developed and introduced into the field of stem cell therapy. Future explorations into potency assays to estimate the system's potential and refine the design process of NMs will require an even tighter coupling of material science with molecular and developmental biology. The future NM design for stem cell therapy is to enhance stem cell induction through nanomaterial composition. Considering the weak induction of NMs themselves, combine the bioactive NMs and inductive agents could achieve high spatial and temporal control of stem cell behavior. Therefore, future studies are necessary to determine the amalgamation of cellular pathways for efficacious induction and potency maintenance in conjunction with the timing of activation. Additionally, some concepts of traditional nanomedicine can be used to design and construct the novel NMs. For example, the development of multifunctional NPs can endow them with diagnostic-imaging and therapeutic performance, thus they can concurrently realize the NP-induced stem cell therapy and the corresponding therapeutic guidance and monitoring by the real-time molecular imaging.

Although the stem cell-NP interaction as well as NPmediated differentiation warrants further investigation, we anticipate that NPs could be widely used to program cell differentiation direction and be still promising for the application in stem cell therapy and will certainly have a breakthrough in the near future.

\section{Conflicts of interest}

There are no conflicts to declare.

\section{Acknowledgements}

This study is financially supported by Southwest hospital foundation (Grant No. SWH2016JCYB-04), Third Military Medical University (Grant No. 2016XPY12) and the Natural Science Foundation of China (51673171).

\section{References}

1 F. M. Watt and R. R. Driskell, Philos. Trans. R. Soc., B, 2010, 365, 155. 
2 P. J. Tesar, J. G. Chenoweth, F. A. Brook, T. J. Davies, E. P. Evans, D. L. Mack, R. L. Gardner and R. D. Mckay, Nature, 2007, 448, 196-199.

3 E. Dawson, G. Mapili, K. Erickson, S. Taqvi and K. Roy, J. Mater. Chem., 2008, 60, 215-228.

4 P. Kerativitayanan, J. K. Carrow and A. K. Gaharwar, $A d v$. Healthcare Mater., 2015, 4, 1600-1627.

5 A. G. Bang and M. K. Carpenter, Science, 2008, 320, 58-59.

6 H. Mizuno, M. Tobita and A. C. Uysal, Stem Cells, 2012, 30, 804-810.

7 J. Ringe, C. Kaps, G. R. Burmester and M. Sittinger, Sci. Nat., 2002, 89, 338-351.

8 V. Mailänder and K. Landfester, Biomacromolecules, 2009, 10, 2379-2400.

9 D. P. Cormode, P. A. Jarzyna, W. J. Mulder and Z. A. Fayad, Adv. Drug Delivery Rev., 2010, 62, 329-338.

10 J. Nicolas, S. Mura, D. Brambilla, N. Mackiewicz and P. Couvreur, ChemInform, 2013, 44, 1147-1235.

11 Q. Wang, H. Cheng, H. Peng, H. Zhou, P. Y. Li and R. Langer, Adv. Drug Delivery Rev., 2015, 91, 125-140.

12 H. Peng, C. Wang, X. Xu, C. Yu and Q. Wang, Nanoscale, 2015, 7, 4354-4360.

13 K. K. Liu, C. C. Wang, C. L. Cheng and J. I. Chao, Biomaterials, 2009, 30, 4249-4259.

14 M. Barrow, A. Taylor, P. Murray, M. J. Rosseinsky and D. J. Adams, Chem. Soc. Rev., 2015, 44, 6733.

15 J. Li, W. Y. Lee, T. Wu, J. Xu, K. Zhang, G. Li, J. Xia and L. Bian, Adv. Healthcare Mater., 2016, 5, 1049-1057.

16 C. Wang, L. Cheng, H. Xu and Z. Liu, Biomaterials, 2012, 33, 4872-4881.

17 C. Liang, C. Wang, X. Ma, Q. Wang, Y. Cheng, H. Wang, Y. Li and Z. Liu, Adv. Funct. Mater., 2013, 23, 272-280.

18 K. E. Sapsford, W. R. Algar, L. Berti, K. B. Gemmill, B. J. Casey, E. Oh, M. H. Stewart and I. L. Medintz, Chem. Rev., 2013, 113, 1904-2074.

19 S. Bhattacharya and S. K. Samanta, ACS Appl. Mater. Interfaces, 2016, 8, 21512.

20 N. L. Rosi and C. A. Mirkin, Chem. Rev., 2005, 105, 15471562.

21 B. R. Smith and S. S. Gambhir, Chem. Rev., 2017, 117, 901986.

22 W. Chrzanowski, J. H. Lee, A. Kondyurin, M. S. Lord, J. H. Jang, H. W. Kim and M. M. M. Bilek, Adv. Funct. Mater., 2015, 25, 339.

23 A. K. Gaharwar, S. M. Mihaila, A. Swami, A. Patel, S. Sant, R. L. Reis, A. P. Marques, M. E. Gomes and A. Khademhosseini, Adv. Mater., 2013, 25, 3329-3336.

24 J. Li, X. Li, J. Zhang, N. Kawazoe and G. Chen, Adv. Healthcare Mater., 2017, DOI: 10.1002/adhm.201700317.

25 J. H. Lee, W. Shim, K. N. Choolakadavil, W. S. Kang, M. Lee, H. S. Kim, J. Choi, G. Lee and J. H. Kim, ACS Appl. Mater. Interfaces, 2015, 7, 1560.

26 S. Namgung, K. Y. Baik, J. Park and S. Hong, ACS Nano, 2011, 5, 7383-7390.

27 H. Clevers, Science, 2015, 350, 1319-1320.

28 K. Y. Dong, S. S. Nanda, K. Kim and S. T. Selvan, J. Mater. Chem. B, 2017, 5, 9429-9451.
29 X. Wang, H. Gan and T. Sun, Adv. Funct. Mater., 2011, 21, 3276-3281.

30 D. I. Bilko, S. V. Malysheva, G. V. Budash, O. V. Chaplya and N. M. Bilko, Probl. Environ. Biotechnol., 2012, 2012, 1.

31 L. Kang, J. Wang, Y. Zhang, Z. Kou and S. Gao, Cell Stem Cell, 2009, 5, 135-138.

32 X.-y. Zhao, W. Li, Z. Lv, L. Liu, M. Tong, T. Hai, J. Hao, C.-l. Guo, Q.-w. Ma, L. Wang, F. Zeng and Q. Zhou, Nature, 2009, 461, 86-90.

33 H. Peng, N. Poovaiah, M. Forrester, E. Cochran and Q. Wang, ACS Biomater. Sci. Eng., 2015, 1, 37-42.

34 H. Peng, X. Liu, R. Wang, F. Jia, L. Dong and Q. Wang, J. Mater. Chem. B, 2014, 2, 6435-6461.

35 C. A. Schütz, L. Juillerat-Jeanneret, H. Mueller, I. Lynch, M. Riediker and N. I. Consortium, Nanomedicine, 2013, 8, 449-467.

36 S. J. Hurst, Methods Mol. Biol., 2011, 726, 1.

37 K. Peynshaert, B. B. Manshian, F. Joris, K. Braeckmans, S. C. De Smedt, J. Demeester and S. J. Soenen, Chem. Rev., 2014, 114, 7581-7609.

38 T. Cedervall, I. Lynch, S. Lindman, T. Berggård, E. Thulin, H. Nilsson, K. A. Dawson and S. Linse, Proc. Natl. Acad. Sci. U. S. A., 2007, 104, 2050-2055.

39 C. Burda, X. Chen, R. Narayanan and M. A. El-Sayed, Chem. Rev., 2005, 105, 1025-1102.

40 W. C. W. Chan, D. J. Maxwell, X. Gao, R. E. Bailey, M. Han and S. Nie, Curr. Opin. Biotechnol., 2002, 13, 40-46.

41 M. Philip, Rep. Prog. Phys., 2001, 64, 297.

42 M. Edmundson, N. T. K. Thanh and B. Song, Theranostics, 2013, 3, 573-582.

43 L. Li, W. Jiang, K. Luo, H. Song, F. Lan, Y. Wu and Z. Gu, Theranostics, 2013, 3, 595-615.

44 J. H. Lee, Y. M. Huh, Y. W. Jun, J. W. Seo, J. T. Jang, H. T. Song, S. Kim, E. J. Cho, H. G. Yoon, J. S. Suh and J. Cheon, Nat. Med., 2007, 13, 95-99.

45 J. E. Gagner, M. D. Lopez, J. S. Dordick and R. W. Siegel, Biomaterials, 2011, 32, 7241-7252.

46 E. Syková and P. Jendelová, Neurodegener. Dis., 2006, 3, 6267.

47 D. P. Yang and D. X. Cui, Chem.-Asian J., 2008, 3, 20102022.

48 T. J. Daou, L. Li, P. Reiss, V. r. Josserand and I. Texier, Langmuir, 2009, 25, 3040-3044.

49 M. S. Hans-Jörg Schneider, Smart Materials for Tissue Engineering: Fundamental Principles, Royal Society of Chemistry, 2016, pp. 1-636.

50 L. Accomasso, C. Gallina, V. Turinetto and C. Giachino, Stem Cells Int., 2016, 2016, 7920358.

51 Jasmin, G. T. de Souza, R. A. Louzada, P. H. Rosado-deCastro, R. Mendez-Otero and A. C. Campos de Carvalho, Int. J. Nanomed., 2017, 12, 779-793.

52 R. T. Castaneda, A. Khurana, R. Khan and H. E. DaldrupLink, J. Visualized Exp., 2011, e3482, DOI: 10.3791/3482.

53 D. Karussis, C. Karageorgiou, A. Vaknin-Dembinsky, B. Gowda-Kurkalli and J. M. Gomori, Arch. Neurol., 2010, 67, 1187-1194. 
54 K. Baek, C. Tu, J. Zoldan and L. J. Suggs, Curr. Stem Cell Rep., 2016, 2, 52-61.

55 A. Bhasin, M. V. Padma Srivastava, S. Mohanty, R. Bhatia, S. S. Kumaran and S. Bose, Clin. Neurol. Neurosurg., 2013, 115, 1003-1008.

56 J. C. Garbern and R. T. Lee, Cell Stem Cell, 2013, 12, 689698.

57 P. Chhabra and K. L. Brayman, Stem Cells Transl. Med., 2013, 2, 328-336.

58 B. O. Diekman and F. Guilak, Curr. Opin. Rheumatol., 2013, 25, 119-126.

59 X. Li, X. Liu, D. Shi and X. Wen, J. Biomed. Nanotechnol., 2015, 11, 1107-1123.

60 S. Agrawal and Q. Zhao, Curr. Opin. Chem. Biol., 1998, 2, 519-528.

61 E. Z. Szuts and F. I. Harosi, Arch. Biochem. Biophys., 1991, 287, 297-304.

62 M. Wei, S. Li and W. Le, J. Nanobiotechnol., 2017, 15, 75.

63 M. A. Mintzer and E. E. Simanek, Chem. Rev., 2009, 109, 259-302.

64 J. Maia, T. Santos, S. Aday, F. Agasse, L. Cortes, J. O. Malva, L. Bernardino and L. Ferreira, ACS Nano, 2011, 5, 97-106.

65 Z.-K. Cui, J. Fan, S. Kim, O. Bezouglaia, A. Fartash, B. M. Wu, T. Aghaloo and M. Lee, J. Controlled Release, 2015, 217, 42-52.

66 S. Pulavendran, C. Rose and A. B. Mandal, J. Nanobiotechnol., 2011, 9, 15.

67 D. Liu, X. He, K. Wang, C. He, H. Shi and L. Jian, Bioconjugate Chem., 2010, 21, 1673-1684.

68 M. Ren, Z. Han, J. Li, G. Feng and S. Ouyang, Mater. Sci. Eng., C, 2015, 56, 348-355.

69 J.-W. Cho, C.-Y. Lee and Y. Ko, J. Gastroenterol. Hepatol., 2012, 27, 1362-1370.

70 K. Peynshaert, B. B. Manshian, F. Joris, K. Braeckmans, S. C. D. Smedt, J. Demeester and S. J. Soenen, Chem. Rev., 2014, 114, 7581-7609.

71 H. Peng, X. Liu, G. Wang, M. Li, K. M. Bratlie, E. Cochran and Q. Wang, J. Mater. Chem. B, 2015, 3, 6856-6870.

72 A. D. Bangham, M. M. Standish and G. Weissmann, J. Mol. Biol., 1965, 13, 253.

73 A. D. Bangham, M. M. Standish and N. Miller, Nature, 1965, 208, 1295.

74 T. X. Nguyen, L. Huang, M. Gauthier, G. Yang and Q. Wang, Nanomedicine, 2016, 11, 1169.

75 F. Song, X. Li, Q. Wang, L. Liao and C. Zhang, J. Biomed. Nanotechnol., 2015, 11, 40.

76 F. Jia, X. Liu, L. Li, S. Mallapragada, B. Narasimhan and Q. Wang, J. Controlled Release, 2013, 172, 1020-1034.

77 M. H. Li, H. Yu, T. F. Wang, N. D. Chang, J. Q. Zhang, D. Du, M. F. Liu, S. L. Sun, R. Wang and H. Q. Tao, J. Mater. Chem. $B, 2014,2$, 1619-1625.

78 Y. S. Takeda, M. Wang, P. Deng and Q. Xu, Bioeng. Transl. Med., 2016, 1, 160-167.

79 M. M. van Schooneveld, A. Gloter, O. Stephan, L. F. Zagonel, R. Koole, A. Meijerink, W. J. Mulder and F. M. de Groot, Nat. Nanotechnol., 2010, 5, 538-544.
80 S.-C. Hsieh, F.-F. Wang, C.-S. Lin, Y.-J. Chen, S.-C. Hung and Y.-J. Wang, Biomaterials, 2006, 27, 1656-1664.

81 O. Seleverstov, O. Zabirnyk, M. Zscharnack, L. Bulavina, M. Nowicki, J.-M. Heinrich, M. Yezhelyev, F. Emmrich, R. O'Regan and A. Bader, Nano Lett., 2006, 6, 2826-2832.

82 S. Chabra, M. Ranjan, R. Bhandari, T. Kaur, M. Aggrawal, V. Puri, N. Mahajan, I. P. Kaur, S. Puri and R. C. Sobti, J. Stem Cells Regen. Med., 2011, 7, 75.

83 J. U. Jung, K. Ko, D. H. Lee, K. Ko, K. T. Chang and Y. K. Choo, Exp. Mol. Med., 2009, 41, 935.

84 B. Corradetti, P. Freile, S. Pells, P. Bagnaninchi, J. Park, T. M. Fahmy and P. A. de Sousa, Biomaterials, 2012, 33, 6634-6643.

85 J. H. Kim, S. P. Ji, N. Y. Han, D. G. Woo, Y. J. Su, H. J. Do, H. Y. Lim, J. M. Kim and K. H. Park, Biomaterials, 2011, 32, 268-278.

86 J. S. Park, H. N. Yang, D. G. Woo, S. Y. Jeon, H. J. Do, H. Y. Lim, J. H. Kim and K. H. Park, Biomaterials, 2011, 32, 3679-3688.

87 S. M. Lim, S. H. Oh, H. H. Lee, S. H. Yuk, G. I. Im and H. L. Jin, J. Mater. Sci.: Mater. Med., 2010, 21, 2593-2600.

88 M. Santoro, A. M. Tatara and A. G. Mikos, J. Controlled Release, 2014, 190, 210-218.

89 S. Shrestha, A. Diogenes and A. Kishen, J. Endod., 2015, 41, 1253-1258.

90 G. F. Li, J. C. Wang, X. M. Feng, Z. D. Liu, C. Y. Jiang and J. D. Yang, Appl. Biochem. Biotechnol., 2015, 175, 3244-3257.

91 S. Pulavendran, M. Rajam, C. Rose and A. B. Mandal, IET Nanobiotechnol., 2010, 4, 51-60.

92 S. Al-Qadi, M. Alatorre-Meda, E. M. Zaghloul, P. Taboada and C. Remunán-López, Colloids Surf., B, 2013, 103, 615623.

93 G. Wu, C. Feng, G. Hui, Z. Wang, J. Tan, L. Luo, X. Peng, Q. Wang and X. Chen, Carbohydr. Polym., 2016, 138, 49.

94 J. M. Oliveira, A. S. Rui, N. Kotobuki, M. Tadokoro, M. Hirose, J. F. Mano, L. R. Rui and H. Ohgushi, Biomaterials, 2009, 30, 804-813.

95 J. M. Oliveira, N. Kotobuki, M. Tadokoro, M. Hirose, J. F. Mano, R. L. Reis and H. Ohgushi, Bone, 2010, 46, 1424-1435.

96 J. M. Oliveira, R. A. Sousa, N. Kotobuki, M. Tadokoro, M. Hirose, J. F. Mano, R. L. Reis and H. Ohgushi, Biomaterials, 2009, 30, 804-813.

97 J. M. Oliveira, R. A. Sousa, P. B. Malafaya, S. S. Silva, N. Kotobuki, M. Hirose, H. Ohgushi, J. F. Mano and R. L. Reis, J. Nanomed. Nanotechnol., 2011, 7, 914-924.

98 S. A. Papadimitriou, M. P. Robin, D. Ceric, R. K. O'Reilly, S. Marino and M. Resmini, Nanoscale, 2016, 8, 1734017349.

99 D. Chen, Q. Li, Z. Meng, L. Guo, Y. Tang, Z. Liu, S. Yin, W. Qin, Z. Yuan, X. Zhang and C. Wu, Theranostics, 2017, 7, 1820-1834.

100 L. Florez, C. Herrmann, J. M. Cramer, C. P. Hauser, K. Koynov, K. Landfester, D. Crespy and V. Mailänder, Small, 2012, 8, 2222-2230. 
101 X. Jiang, J. Dausend, M. Hafner, A. Musyanovych, C. Röcker, K. Landfester, V. Mailänder and G. U. Nienhaus, Biomacromolecules, 2010, 11, 748-753.

102 P. Jiang, D. Yu, W. Zhang, Z. Mao and C. Gao, RSC Adv., 2015, 5, 40924-40931.

103 S. Huang, X. Song, T. Li, J. Xiao, Y. Chen, X. Gong, W. Zeng, L. Yang and C. Chen, Stem Cell Res. Ther., 2017, 8, 264.

104 W. Ma, X. Shao, D. Zhao, Q. Li, M. Liu, T. Zhou, X. Xie, C. Mao, Y. Zhang and Y. Lin, ACS Appl. Mater. Interfaces, 2018, 10, 7892-7900.

105 X. R. Shao, S. Y. Lin, Q. Peng, S. R. Shi, X. L. Li, T. Zhang and Y. F. Lin, J. Nanomed. Nanotechnol., 2017, 13, 1809-1819.

106 P. Baglioni, E. Carretti and D. Chelazzi, Nat. Nanotechnol., 2015, 10, 287-290.

107 E. C. Dreaden, L. A. Austin, M. A. Mackey and M. A. ElSayed, Ther. Delivery, 2012, 3, 457-478.

108 J. Yang, T. Ling, W. T. Wu, H. Liu, M. R. Gao, C. Ling, L. Li and X. W. Du, Nat. Commun., 2013, 4, 1695.

109 M. Mahmoudi, S. Sant, B. Wang, S. Laurent and T. Sen, Adv. Drug Delivery Rev., 2011, 63, 24-46.

110 J. Zheng, P. R. Nicovich and R. M. Dickson, Annu. Rev. Phys. Chem., 2007, 58, 409.

111 M. F. De Volder, S. H. Tawfick, R. H. Baughman and A. J. Hart, Science, 2013, 339, 535-539.

112 S. Labbaf, O. Tsigkou, K. H. Müller, M. M. Stevens, A. E. Porter and J. R. Jones, Biomaterials, 2011, 32, 10101018.

113 O. Tsigkou, S. Labbaf, M. M. Stevens, A. E. Porter and J. R. Jones, Adv. Healthcare Mater., 2014, 3, 115-125.

114 L. Chen, J. M. Mccrate, J. C. Lee and H. Li, Nanotechnology, 2011, 22, 105708.

115 Y. K. Liu, G. C. Wang, Y. R. Cai, H. J. Ji, G. S. Zhou, X. L. Zhao, R. K. Tang and Z. Ming, J. Biomed. Mater. Res., Part A, 2009, 90, 1083-1091.

116 A. K. Gaharwar, S. M. Mihaila, A. Swami, A. Patel, S. Sant, R. L. Reis, A. P. Marques, M. E. Gomes and A. Khademhosseini, Adv. Mater., 2013, 25, 3329-3336.

117 K. J. Kim, Y. A. Joe, M. K. Kim, S. J. Lee, Y. H. Ryu, D. W. Cho and J. W. Rhie, Int. J. Nanomed., 2015, 10, 2261-2272.

118 D. A. Stout and T. J. Webster, Mater. Today, 2012, 15, 312318.

119 T. R. Nayak, L. Jian, L. C. Phua, H. K. Ho, Y. Ren and G. Pastorin, ACS Nano, 2010, 4, 7717-7725.

120 E. Mooney, P. Dockery, U. Greiser, M. Murphy and V. Barron, Nano Lett., 2008, 8, 2137-2143.

121 C. Y. Tay, H. Gu, S. L. Wen, H. Yu, H. Q. Li, B. C. Heng, H. Tantang, S. C. J. Loo, L. J. Li and L. P. Tan, Carbon, 2010, 48, 1095-1104.

122 L. Meng, R. Chen, A. Jiang, L. Wang, P. Wang, C. Z. Li, R. Bai, Y. Zhao, H. Autrup and C. Chen, Small, 2013, 9, 1413.

123 D. Liu, C. Yi, D. Zhang, J. Zhang and M. Yang, ACS Nano, 2010, 4, 2185-2195.

124 O. Akhavan, E. Ghaderi and A. Akhavan, Biomaterials, 2012, 33, 8017-8025.

125 O. Akhavan, E. Ghaderi, H. Emamy and F. Akhavan, Carbon, 2013, 54, 419-431.
126 E. Hashemi, O. Akhavan, M. Shamsara, M. Daliri, M. Dashtizad and A. Farmany, Colloids Surf., B, 2016, 146, 770-776.

127 S. Syama, C. Aby, T. Maekawa, D. Sakthikumar and P. Mohanan, 2D Materials, 2017, 4, 025066.

128 W. Shang, X. Zhang, M. Zhang, Z. Fan, Y. Sun, M. Han and L. Fan, Nanoscale, 2014, 6, 5799-5806.

129 J. Kim, S. H. Song, Y. Jin, H. J. Park, H. Yoon, S. Jeon and S. W. Cho, Nanoscale, 2016, 8, 8512-8519.

130 L. Jin, J. H. Lee, O. S. Jin, Y. C. Shin, M. J. Kim, S. W. Hong, M. H. Lee, J. C. Park and D. W. Han, J. Nanosci. Nanotechnol., 2015, 15, 7966.

131 D. Yang, T. Li, M. Xu, F. Gao, J. Yang, Z. Yang and W. Le, Nanomedicine, 2014, 9, 2445-2455.

132 J. Kim, K. Yang, J. S. Lee, Y. H. Hwang, H. J. Park, K. I. Park, D. Y. Lee and S. W. Cho, Macromol. Biosci., 2017, DOI: 10.1002/mabi.201600540.

133 W. C. Lee, C. H. Lim, H. Shi, L. A. Tang, Y. Wang, C. T. Lim and K. P. Loh, ACS Nano, 2011, 5, 7334-7341.

134 X. Yan, W. Yang, Z. Shao, S. Yang and X. Liu, Int. J. Nanomed., 2016, 11, 5473-5484.

135 A. Gruber, Science, 2012, 276, 2012-2014.

136 Y. Xing and L. Dai, Nanomedicine, 2009, 4, 207-218.

137 Y. Xing, W. Xiong, L. Zhu, E. Osawa, S. Hussin and L. Dai, ACS Nano, 2011, 5, 2376-2384.

138 S. P. Blaber, C. J. Hill, R. A. Webster, J. M. Say, L. J. Brown, S. C. Wang, G. Vesey and B. R. Herbert, PLoS One, 2013, 8, e52997.

139 T. C. Hsu, K. K. Liu, H. C. Chang, E. Hwang and J. I. Chao, Sci. Rep., 2014, 4, 5004.

140 J. Xie, S. Lee and X. Chen, Adv. Drug Delivery Rev., 2010, 62, 1064-1079.

141 M. Ovais, A. T. Khalil, A. Raza, M. A. Khan, I. Ahmad, N. U. Islam, M. Saravanan, M. F. Ubaid, M. Ali and Z. K. Shinwari, Nanomedicine, 2016, 12, 3157-3177.

142 H. Wei, O. T. Bruns, M. G. Kaul, E. C. Hansen, M. Barch, A. Wiśniowska, O. Chen, Y. Chen, N. Li and S. Okada, Proc. Natl. Acad. Sci. U. S. A., 2017, 114, 2325.

143 K. Kakinoki, K. Yamane, M. Igarashi, M. Yamamoto, R. Teraoka and Y. Matsuda, Chem. Pharm. Bull., 2005, 53, 811-815.

144 C. Yi, D. Liu, C. C. Fong, J. Zhang and M. Yang, ACS Nano, 2010, 4, 6439-6448.

145 S. Y. Choi, S. S. Min, D. R. Pan, A. T. N. Lam, S. W. Joo and S. Y. Lee, Int. J. Nanomed., 2015, 10, 4383.

146 W. K. Ko, N. H. Dong, H. J. Moon, J. L. Sang, S. B. Min, J. B. Lee, I. C. Sun, H. B. Jeon, H. K. Park and I. K. Kwon, J. Colloid Interface Sci., 2015, 438, 68-76.

147 J. Li, J. J. Li, J. Zhang, X. Wang, N. Kawazoe and G. Chen, Nanoscale, 2016, 8, 7992-8007.

148 J. Li, Y. Chen, Y. Yang, N. Kawazoe and G. Chen, J. Mater. Chem. B, 2017, 5, 1353-1362.

149 J. E. J. Li, N. Kawazoe and G. Chen, Biomaterials, 2015, 54, 226-236.

150 J. Deng, H. Zheng, X. Zheng, M. Yao, Z. Li and C. Gao, Nano Res., 2016, 9, 3683-3694. 
151 R. Zhang, P. Lee, V. C. Lui, Y. Chen, X. Liu, C. N. Lok, M. To, K. W. Yeung and K. K. Wong, J. Nanomed. Nanotechnol., 2015, 11, 1949.

152 R. Zhang, The University of Hong Kong, 2015, DOI: 10.5353/ th_b5558999.

153 P. Rajanahalli, C. J. Stucke and Y. Hong, Toxicol. Rep., 2015, 2, 758-764.

154 R. J. Cooper, M.S. thesis, Theses, Dissertations and Capstones, Marshall University Marshall Digital Scholar, 2016, 1014.

155 Q. Hui, Z. Chen, Z. An, J. Yao, Y. Zhao, J. Wang, L. Xin, H. Bing, X. Zhang and W. Yang, Int. J. Nanomed., 2014, 2014, 2469.

156 L. Pauksch, M. Rohnke, R. Schnettler and K. S. Lips, Toxicol. Rep., 2014, 1, 900-908.

157 Q. Wang, B. Chen, F. Ma, S. Lin, M. Cao, Y. Li and N. Gu, Nano Res., 2016, 1-17.

158 Q. Wang, B. Chen, M. Cao, J. Sun, H. Wu, P. Zhao, J. Xing, Y. Yang, X. Zhang and M. Ji, Biomaterials, 2016, 86, 11.

159 S. Shrestha, P. Jiang, M. H. Sousa, P. C. Morais, Z. Mao and C. Gao, J. Mater. Chem. B, 2015, 4, 245-256.

160 P. Jiang, Y. Zhang, C. Zhu, W. Zhang, Z. Mao and C. Gao, Acta Biomater., 2016, 46, 141-150.

161 S. Syama, P. J. Sreekanth, H. K. Varma and P. V. Mohanan, Toxicol. Mech. Methods, 2014, 24, 644.

162 M. Orazizadeh, A. Khodadadi, V. Bayati, S. Saremy, M. Farasat and L. Khorsandi, Cell J., 2015, 17, 412-421.

163 X. Deng, Q. Luan, W. Chen, Y. Wang, M. Wu, H. Zhang and Z. Jiao, Nanotechnology, 2009, 20, 115101.

164 T. Foroutan, Nanomed. J., 2014, 1, 308-314.

165 Y. Hu, K. Cai, Z. Luo, D. Xu, D. Xie, Y. Huang, W. Yang and P. Liu, Acta Biomater., 2012, 8, 439-448.

166 X. Liu, X. Ren, X. Deng, Y. Huo, J. Xie, H. Huang, Z. Jiao, M. Wu, Y. Liu and T. Wen, Biomaterials, 2010, 31, 3063.

167 Y. Hou, K. Cai, J. Li, X. Chen, M. Lai, Y. Hu, Z. Luo, X. Ding and D. Xu, Int. J. Nanomed., 2013, 8, 3619.

168 S. Shrestha, Z. Mao, Y. Fedutik and C. Gao, J. Mater. Chem. $B, 2016$, 4, 6955-6966.

169 W. Zhang, P. Jiang, W. Chen, B. Zheng, Z. Mao, A. Antipov, M. Correia, E. H. Larsen and C. Gao, J. Nanosci. Nanotechnol., 2016, 16, 5489.
170 G. Zhou, G. Gu, Y. Li, Q. Zhang, W. Wang, S. Wang and J. Zhang, Biol. Trace Elem. Res., 2013, 153, 411.

171 A. Rocca, V. Mattoli, B. Mazzolai and G. Ciofani, Pharm. Res., 2014, 31, 2952-2962.

172 F. Zhao, Y. Zhao, Y. Liu, X. Chang, C. Chen and Y. Zhao, Small, 2011, 7, 1322-1337.

173 I. Ilie, R. Ilie, T. Mocan, D. Bartos and L. Mocan, Int. J. Nanomed., 2012, 7, 2211.

174 J. Deng, Y. U. Dahai and C. Y. Gao, Sci. China: Chem., 2013, 56, 1533-1541.

175 W. K. Ko, N. H. Dong, H. J. Moon, J. L. Sang, S. B. Min, J. B. Lee, I. C. Sun, H. B. Jeon, H. K. Park and I. K. Kwon, J. Colloid Interface Sci., 2015, 438, 68-76.

176 P. Riveragil, d. A. D. Jimenez, V. Wulf, B. Pelaz, P. P. Del, Y. Zhao, D. L. F. Jm, d. L. I. Ruiz, T. Rojo and X. J. Liang, Acc. Chem. Res., 2013, 46, 743-749.

177 L. Florez, C. Herrmann, J. M. Cramer, C. P. Hauser, K. Koynov, K. Landfester, D. Crespy and V. Mailänder, Small, 2012, 8, 2222-2230.

178 Y. Zhang, S. Tekobo, Y. Tu, Q. Zhou, X. Jin, S. A. Dergunov, E. Pinkhassik and B. Yan, ACS Appl. Mater. Interfaces, 2012, 4, 4099-4105.

179 J. M. Seong, B. C. Kim, J. H. Park, I. K. Kwon, A. Mantalaris and Y. S. Hwang, Biomed. Mater., 2010, 5, 062001.

180 B. C. Heng, H. Hkh, E. K. Sim, T. Cao and S. C. Ng, J. Bone Miner. Res., 2004, 19, 1379-1394.

181 S. Lorenz, C. P. Hauser, B. Autenrieth, C. K. Weiss, K. Landfester and V. Mailänder, Macromol. Biosci., 2010, 10, 1034-1042.

182 P. M. Tsimbouri, J. Funct. Biomater., 2015, 6, 598-622.

183 B. Su, S. Mitra, H. Gregg, S. Flavahan, M. Chotani, K. Clark, P. Goldschmidt-Clermont and N. Flavahan, Circ. Res., 2001, 89, 39-46.

184 N. Mody, F. Parhami, T. A. Sarafian and L. L. Demer, Free Radical Biol. Med., 2001, 31, 509-519.

185 G. Ciofani, L. Ricotti, C. Canale, D. D'Alessandro, S. Berrettini, B. Mazzolai and V. Mattoli, Colloids Surf., B, 2013, 102, 312-320.

186 X. Wang, X. Hu, D. M. Ida, K. Naoki, Y. Yang and G. Chen, Sci. Rep., 2016, 6, 28708. 